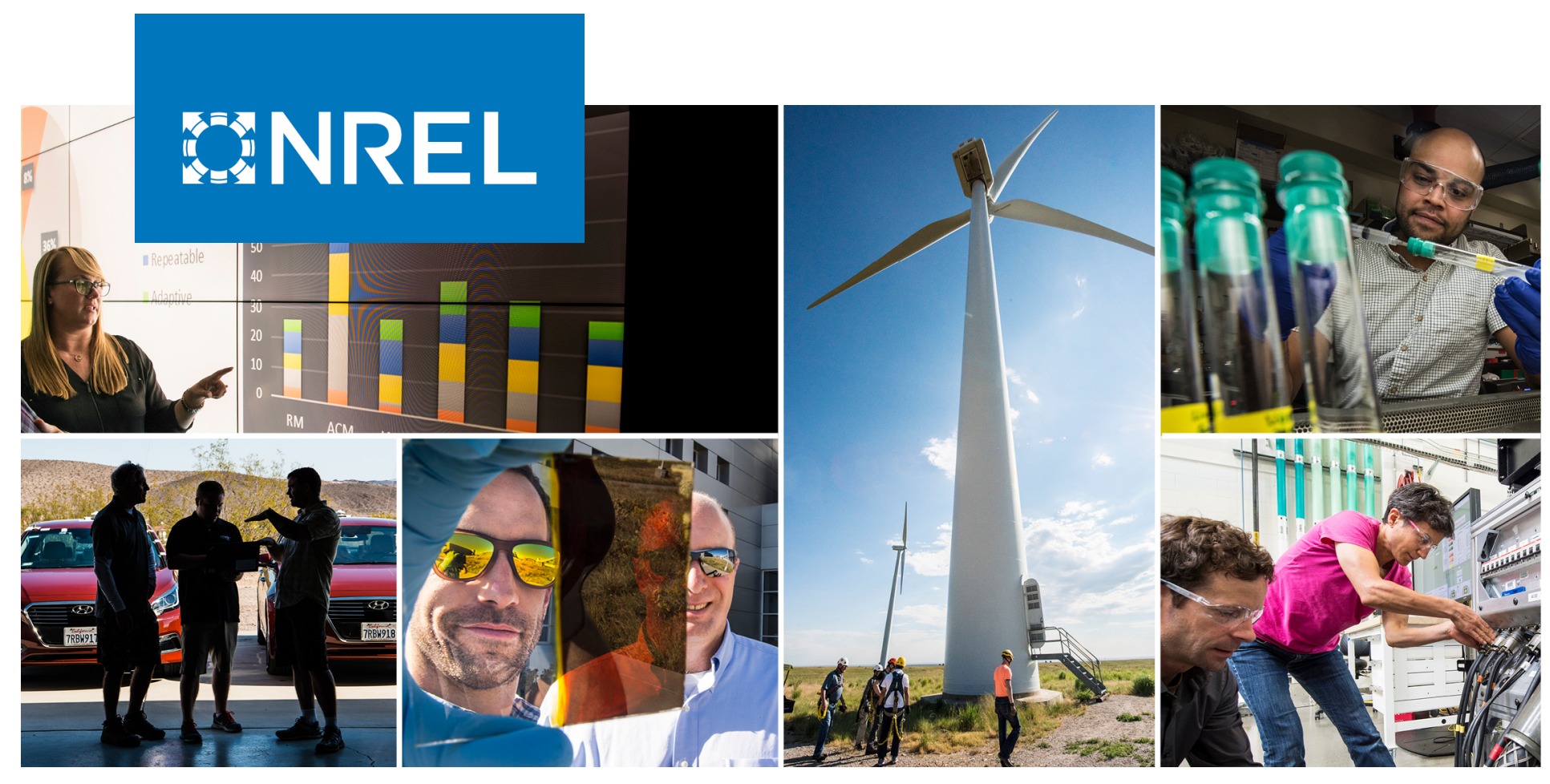

\title{
Methods for Representing Flexible, Energy-Constrained Technologies in Utility Planning Tools
}

Elaine Hale, Brady Cowiestoll, Jennie Jorgenson, Trieu Mai, and Dylan Hettinger

National Renewable Energy Laboratory

NREL is a national laboratory of the U.S. Department of Energy Office of Energy Efficiency \& Renewable Energy

Operated by the Alliance for Sustainable Energy, LLC

This report is available at no cost from the National Renewable Energy Laboratory (NREL) at www.nrel.gov/publications.
Technical Report

NREL/TP-6A20-72120

April 2021 


\section{BNREL}

\section{Methods for Representing Flexible, Energy-Constrained Technologies in Utility Planning Tools}

Elaine Hale, Brady Cowiestoll, Jennie Jorgenson, Trieu Mai, and Dylan Hettinger

National Renewable Energy Laboratory

\section{Suggested Citation}

Hale, Elaine, Brady Cowiestoll, Jennie Jorgenson, Trieu Mai, and Dylan Hettinger. 2021. Methods for Representing Flexible Technologies in Utility Planning Tools. Golden, CO: National Renewable Energy Laboratory. NREL/TP-6A20-72120,

https://www.nrel.gov/docs/fy21osti/72120.pdf.

NREL is a national laboratory of the U.S. Department of Energy Office of Energy Efficiency \& Renewable Energy Operated by the Alliance for Sustainable Energy, LLC

This report is available at no cost from the National Renewable Energy Laboratory (NREL) at www.nrel.gov/publications.

Contract No. DE-AC36-08GO28308
Technical Report

NREL/TP-6A20-72120

April 2021

National Renewable Energy Laboratory 15013 Denver West Parkway Golden, CO 80401 303-275-3000 • www.nrel.gov 


\section{NOTICE}

This work was authored by the National Renewable Energy Laboratory, operated by Alliance for Sustainable Energy, LLC, for the U.S. Department of Energy (DOE) under Contract No. DE-AC36-08GO28308. Funding provided by the U.S. Department of Energy Office of Energy Efficiency and Renewable Energy Solar Energy Technologies Office. The views expressed herein do not necessarily represent the views of the DOE or the U.S. Government.

This report is available at no cost from the National Renewable Energy Laboratory (NREL) at www.nrel.gov/publications.

U.S. Department of Energy (DOE) reports produced after 1991 and a growing number of pre-1991 documents are available free via www.OSTI.gov.

Cover Photos by Dennis Schroeder: (clockwise, left to right) NREL 51934, NREL 45897, NREL 42160, NREL 45891, NREL 48097, NREL 46526.

NREL prints on paper that contains recycled content. 


\section{Abstract}

Capacity expansion models are widely used by power system researchers, planners, and policy analysts to evaluate alternative power system investment scenarios. With the increasing deployment of wind and solar in the US, there has been much focus on improving the representations of variable generation (VG) technologies within capacity expansion models. Models that capture the variable net-load profiles and larger reserve requirements associated with high penetration VG systems represent an improvement to classic capacity expansion models, but fall short of capturing the complexities associated with storage technologies, such as battery energy storage (BES) and concentrating solar power with thermal energy storage (CSP with TES). While difficult to model in a capacity expansion setting, these technologies are potentially competitive sources of flexibility with the intriguing characteristics of being able to absorb VG that would otherwise be curtailed and directly contribute to renewable energy goals, respectively. In this paper we present methods for accurately representing these technologies in a large-scale capacity expansion model with high electrical and geospatial resolution. VG modeling techniques, including novel methods for capturing curtailment due to unit commitment and other hourly dispatch phenomena, are also reviewed. Modeling for a region in the southwestern United States demonstrates the economic relevance of being able to explicitly trade off the costs and capabilities of energy-constrained technologies, especially BES, against other resources in the near-term, in time to make plans for the coming decade. 


\section{Acknowledgments}

This work was authored by the National Renewable Energy Laboratory, operated by Alliance for Sustainable Energy, LLC, for the U.S. Department of Energy (DOE) under Contract No. DE-AC36-08GO28308. Funding provided by U.S. Department of Energy Office of Energy Efficiency and Renewable Energy Solar Energy Technologies Office. The views expressed in the article do not necessarily represent the views of the DOE or the U.S. Government.

The authors thank Paul Denholm and Mark Mehos (National Renewable Energy Laboratory, NREL) for supporting this work; Craig Turchi and Parthiv Kurup (NREL) for providing CSP modeling inputs; Winnie Fan (NREL, Texas A\&M University) for implementing piecewise curtailment estimates for new VG resources; Jarett Zuboy for editing support; and Cara Marcy, Diego Alejandro Tejada Arango, and John Bistline for their thoughtful reviews. 


\section{Contents}

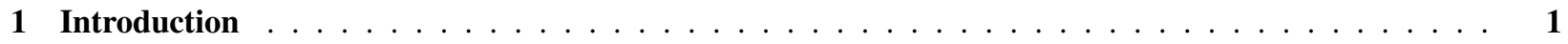

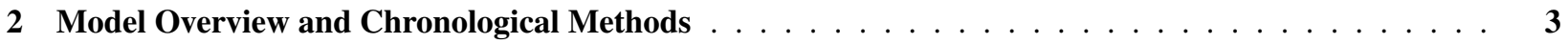

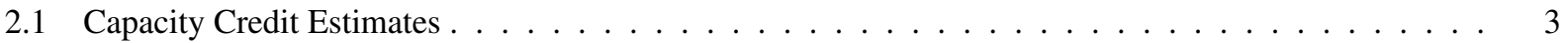

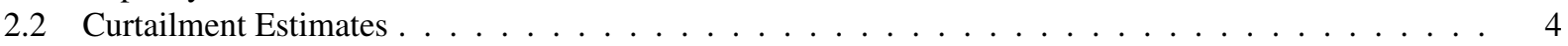

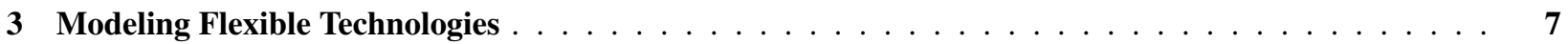

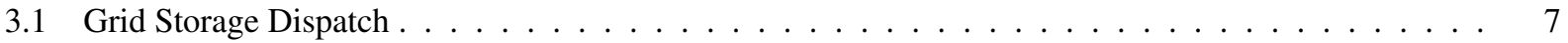

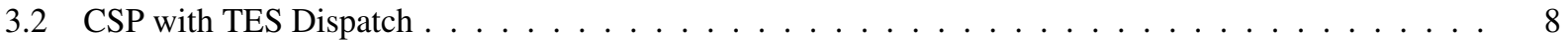

3.3 Grid Storage Capacity Value and Curtailment Reductions . . . . . . . . . . . . . . . . 9

3.4 CSP with TES Capacity Value and Spillage $\ldots \ldots \ldots \ldots \ldots$

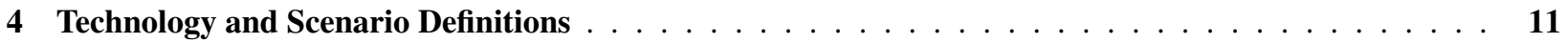

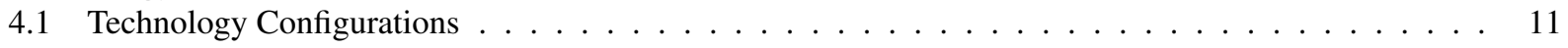

4.2 Scenario Framework $\ldots \ldots \ldots \ldots \ldots \ldots \ldots$

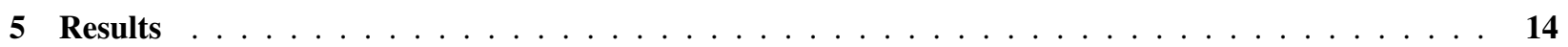

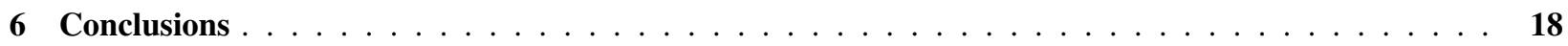

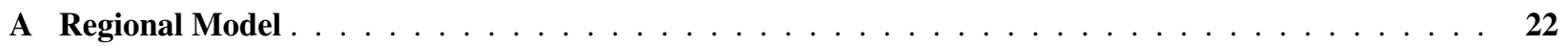

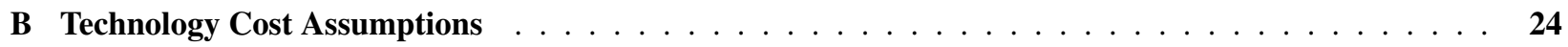

C Pricetaker Analyses to Determine Optimal Configurations $\ldots \ldots \ldots \ldots \ldots \ldots$ 


\section{List of Figures}

Figure 1. Relationship between RPM's investment-optimization model (right) and calculations concerning

VG and flexible technology capacity credits and curtailment impacts (left) . . . . . . . . . . . . 2

Figure 2. Conceptual depiction of the NLDC-based capacity value estimation method . . . . . . . . . . 4

Figure 3. Conceptual depiction of the NLDC-based curtailment estimation method . . . . . . . . . . 5

Figure 4. Example wind and solar marginal curtailment, taken as the average values across all regions . . . 6

Figure 5. Dispatch heuristic for battery storage . . . . . . . . . . . . . . . . . . 9

Figure 6. Optimal (a) BES and (b) CSP with TES configurations computed from a set of RPM scenarios and filtered down to those with positive net value $\ldots \ldots \ldots \ldots$

Figure 7. Focus region 2030 (left) capacity and (right) dispatch without BES and CSP with TES investment

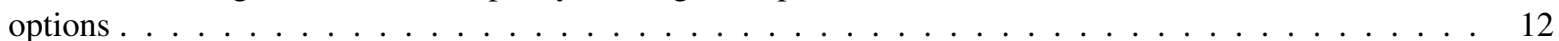

Figure 8. Focus region differences in 2030 (left) capacity and (right) dispatch when flexible investment options for BES and CSP with TES are enabled . . . . . . . . . . . . . . . . . . . . . 14

Figure 9. HCF\&CSP focus region dispatch in 2030 for (top) all services from 4.5h BES and CSP with TES, and (bottom) total system generation . . . . . . . . . . . . . . . . . . . . . . . . .

Figure 10. Reserves provided by technology in 2030 for all scenarios . . . . . . . . . . . . . . . . . 17

Figure 11. Base scenario reserve prices for California in 2030 . . . . . . . . . . . . . . . . . . . . . 17

Figure A.1. RPM is a combined nodal-zonal model for examining regional planning decisions. The focus region for this paper is centered on the United States' highest quality CSP resource. . . . . . . . . . . 23

Figure B.1. Carbon prices used for HCF\&CSP scenario . . . . . . . . . . . . . . . . . . . . . 25

\section{List of Tables}

Table 1. Storage accumulations, transfers, and starting storage levels per dispatch period for the CSP with TES SM 3.8, 14.4 h 2030 builds in the focus region . . . . . . . . . . . . . . . . . 15

Table 2. Storage accumulations, transfers, and starting storage levels per dispatch period for the BES $4.5 \mathrm{~h}$ capacity in the focus region in $2030 \ldots \ldots \ldots$

Table B.1. Technology capital cost assumptions for new generation capacity . . . . . . . . . . . . . . 24

Table B.2. Battery storage configurations and costs . . . . . . . . . . . . . . . . . . . 25

Table B.3. Modeled CSP with TES configurations and costs . . . . . . . . . . . . . . . . . . . 25 


\section{Introduction}

The rapid large-scale deployment of variable generation (VG) technologies-including wind and solar-has stimulated the study of power system flexibility. Flexibility, used here to mean the ability to modulate supply resources or consumption patterns through control responses to dispatch or price signals, enables a power system to accommodate net-load variability and uncertainty, both of which tend to increase with increasing VG penetration. Flexibility has always been supplied by generator unit commitment and dispatch processes, and in the future it may become routine for variable generation to contribute to flexibility supply by providing reserves or altering their dispatch. Nevertheless, energy-constrained resources such as pumped hydroelectric energy storage (PHES), battery energy storage (BES), and concentrating solar power with thermal energy storage (CSP with TES) are potentially competitive sources of flexibility with the intriguing characteristics of being able to absorb variable generation that would otherwise be curtailed and directly contributing to renewable energy goals, respectively. In this paper, we present the methods used by the Resource Planning Model (RPM), a long-term regional utility planning model that considers the impacts of VG on power system economics, to represent these two flexible but energy-constrained technologies.

Numerous studies have assessed the operational value of flexibility. Some have employed production cost models, a key tool for large-scale renewable integration studies, to evaluate the effects of different levels of VG and flexibility on production costs, dispatchable generator operations, and emissions (GE Energy 2010; Lew et al. 2013; EnerNex Corporation 2011; Bloom et al. 2016; E3 2014; Brinkman et al. 2015). Others have used the modeling methodologies of large-scale renewable integration studies to conduct more targeted system flexibility research by incrementally varying system flexibility (Black and Strbac 2006; Palchak and Denholm 2014; Denholm et al. 2013; Jorgenson et al. 2013; Denholm et al. 2016; Stoll, Buechler, and Hale 2017). Additional approaches include pricetaker models for analyzing the revenue of a candidate option under historical or simulated conditions (Graves, Jenkin, and Murphy 1999; Sioshansi et al. 2009) and stochastic production cost models (Hargreaves et al. 2015).

Long-term planning decisions are not generally driven by operational modeling, however. Typically, capacity expansion models (CEMs), which accept initial conditions, technology characteristics, technology costs, operational constraints, and policy constraints as inputs, are first used to compute the amounts and locations of new system components, as well as upgrades and retirements of existing system components, to meet future system needs at minimum cost. Operational models, on the other hand, are used to test feasibility of a future system identified by a CEM and to identify changes that may help the system operate more reliably. As such, it is important for CEMs to represent flexibility needs and contributions so that the bulk-level build-out plan does not overlook challenges associated with net-load variability and uncertainty or miss opportunities to cost-effectively plan for a more flexible system. Indeed, most CEMs do implicitly or explicitly represent flexibility (Ma et al. 2013; Johnston et al. 2013; Short et al. 2011; EPRI 2014; Tejada-Arango et al. 2018; Bistline et al. 2020), but with limited operational detail to manage computing requirements. The resulting simplifications make it difficult to fully capture operational contributions, especially from energy-limited resources.

RPM is a CEM designed to represent renewable energy investment decisions in regional planning processes (Mai et al. 2013) and to serve as a testbed for exploring methodological tradeoffs in such processes (Mai et al. 2015). In order manage computational feasibility while maintaining as much spatial and temporal detail as possible, RPM uses a combined zonal/nodal formulation to enable high resolution in the (nodal) focus region informed by accurate (zonal) boundary conditions. Hourly load, solar, and wind data for flexibly defined dispatch periods representing a full year, combined with co-optimization of investment decisions, transmission-constrained dispatch, and reserves provides highly resolved, detailed insight into VG investment decisions. As described herein ${ }^{1}$, these features are further supplemented with dynamic capacity credit estimation, PCM-informed curtailment estimates, and endogenous treatment of multiple BES and CSP with TES configurations to capture both flexibility needs and flexibility contributions from non-traditional resources. Furthermore, BES and CSP with TES configurations can be selected for investment consideration based on pricetaker analyses of RPM runs.

CSP with TES models are less commonly described in the CEM literature. CSP with TES plants run a thermal generation cycle off of gathered solar thermal energy that is stored in a TES reservoir. From a modeling perspective,

\footnotetext{
${ }^{1}$ Capacity credit and RPM methodologies are also described partially in Hale, Stoll, and Mai (2016)
} 


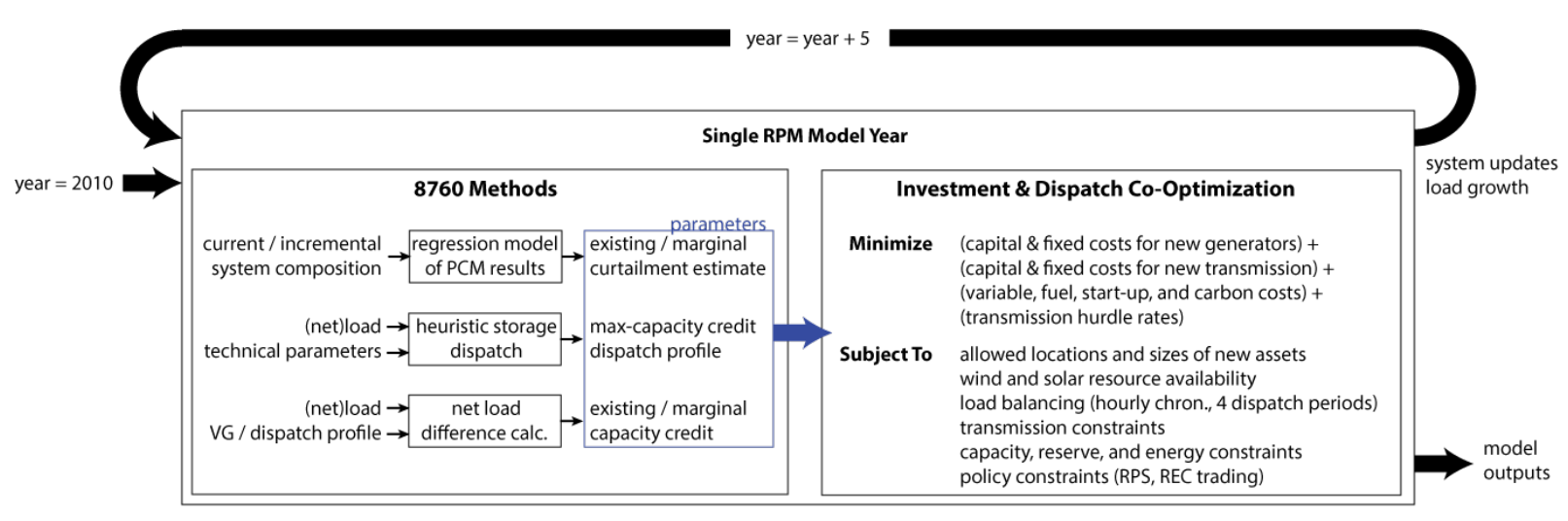

Figure 1. Relationship between RPM's investment-optimization model (right) and calculations concerning VG and flexible technology capacity credits and curtailment impacts (left)

this is captured by charging a storage reservoir from a solar collection profile similar in shape to a PV generation profile. Electricity is generated when the storage reservoir is discharged to run a steam turbine. The energy constraints of the TES are similar to those for BES, the primary exception being that common configurations of CSP with TES plants charge from only the solar array, and may sometimes need to spill available charging energy based on insufficient draw-down of the energy reservoir between diurnal cycles. Thus, the methods for and challenges of modeling CSP with TES are similar to those of modeling BES: energy constraints must be respected at each time-step, and capacity value and curtailment impacts vary with power system composition and technology configuration.

In this paper, after further describing the RPM model with a focus on BES and CSP with TES representation, we demonstrate the impact of modeling investment decisions for a region in the western United States with and without new BES and CSP with TES options. This is done in a framework with high geographic resolution; moderate temporal resolution; and co-optimization of generation, transmission, and storage resources to fulfill a regional electricity system's capacity, energy, ancillary service, and renewable energy policy requirements. ${ }^{2}$ The differences between the results that include these flexibility options and the results that exclude them highlight the importance of accounting for flexibility in long-term system planning. The approaches we use in RPM to improve the representation of flexibility could also be applied to other CEMs.

\footnotetext{
${ }^{2}$ Compared to the modeling needs described in Haas et al. (2017), RPM partially addresses storage technology diversity, includes a high level of temporal and spatial resolution, and allows storage to provide multiple services. RPM does not currently model compressed air energy storage (CAES) or non-lithium ion batteries, capture capacity or efficiency differences between charging and discharging or over a unit's lifetime, or capture distribution- or retail-level value streams/services; it also does not model interactions with other energy system types.
} 


\section{Model Overview and Chronological Methods}

RPM is a CEM designed to investigate the evolution of a regional power system, such as a utility service territory, state, or balancing authority (BA). Distinguished by high resolution modeling within a focus region, RPM is a sequential planning model that co-optimizes generation expansion, transmission expansion, and reduced-order dispatch one year at a time, currently starting in 2010 and continuing to 2035, moving forward in five-year increments. The overall algorithmic structure of RPM is depicted in Figure 1. The least-cost optimization algorithm depicted on the righthand side of that diagram minimizes overall system cost, including capital costs, fixed and variable operations and maintenance (O\&M) costs, and fuel costs. Hourly dispatch is modeled for four days that together represent the low, mid, high, and peak load conditions seen throughout a year. Each hourly step balances generation with load, maintains the required amount of reserve capacity, and remains within operational constraints for individual generators and transmission paths. RPM includes novel methodologies for estimating capacity credits and curtailment impacts, which are depicted on the left-hand side of Figure 1 and are the focus of the remainder of this section. For other model details, including general cost and operational property details, we refer the interested reader to Mai et al. (2015) and Hale, Stoll, and Mai (2016). The version of RPM used for this publication is from September 2018.

Although RPM's reduced-order dispatch period structure can effectively describe average and annual operations, it does not perform as well during tail events such as very high and very low loads-periods during which flexibility often is most desired. In particular, the peak load day is not sufficient to estimate the capacity credits for variable and flexible resources (Madaeni, Denholm, and Sioshansi 2012; Sioshansi, Madaeni, and Denholm 2014), and one average low-load period does not present a sufficiently low net load to fully capture the curtailment experienced over a full year of operations. For this reason, RPM employs additional methods that use all 8,760 hours per year to model VG and flexible technologies more accurately, as shown on the left side of Figure 1. These more detailed calculations estimate the capacity credits for VG and flexible technologies, the expected curtailment of VG technologies, and the curtailment that can be avoided by charging PHES and BES from the grid. These parameters are then used in the optimization problem to ensure that technologies' variability and flexibility is appropriately valued. The following subsections more fully describe RPM's methods for calculating capacity credits and curtailment impacts, which have been recently refined and extended to better represent BES and CSP with TES.

\subsection{Capacity Credit Estimates}

In RPM, the capacity value of variable and flexible generators depends on the time-varying and system-dependent correlation between hourly production and peak net load hours (Madaeni, Sioshansi, and Denholm 2013). This is in contrast to the assumptions made for fully dispatchable resources (e.g., gas capacity), for which full nameplate capacity, less seasonal capacity reductions, is assumed to count toward planning reserves.

To capture a more complete range of variability in system operation, we use the full annual load duration curve (LDC) and net-load duration curve (NLDC) (IEA 2015; Frew et al. 2017) to capture the tail events for existing resources. An incremental load duration curve (ILDC) is calculated independently for each type of potential new VG technology and location. Duration curves are also created for storage and CSP; however these are based on a heuristic dispatch profile, which will be described in detail in section 3.3 and section 3.4, respectively.

The capacity credits for variable resources are estimated by accounting for their average ability to contribute to the capacity needs of the system during the top 100 hours of the year. ${ }^{3}$ A graphical representation of this method is shown in Figure 2. More robust methods can be used to estimate capacity credit (Ibanez and Milligan 2012); however, this method has been demonstrated to be an effective approximation (Madaeni, Denholm, and Sioshansi 2012) and is more straightforward to include within a CEM. More detail on this methodology as implemented in RPM can be found in Hale, Stoll, and Mai (2016).

The peak demand and planning reserve margin determine the system's firm capacity requirement, which is then met by the sum of the seasonal net capacity of fully dispatchable units, the aggregate capacity credits of existing VG and

\footnotetext{
${ }^{3}$ These top hours are calculated separately for each LDC, NLDC, and ILDC, such that the hours under consideration may actually shift between the various load duration curves. This allows us to consider changing net-load shapes as, for example, increased solar power moves the peak hours of a day from the afternoon to evening or storage shifts load away from peak hours.
} 


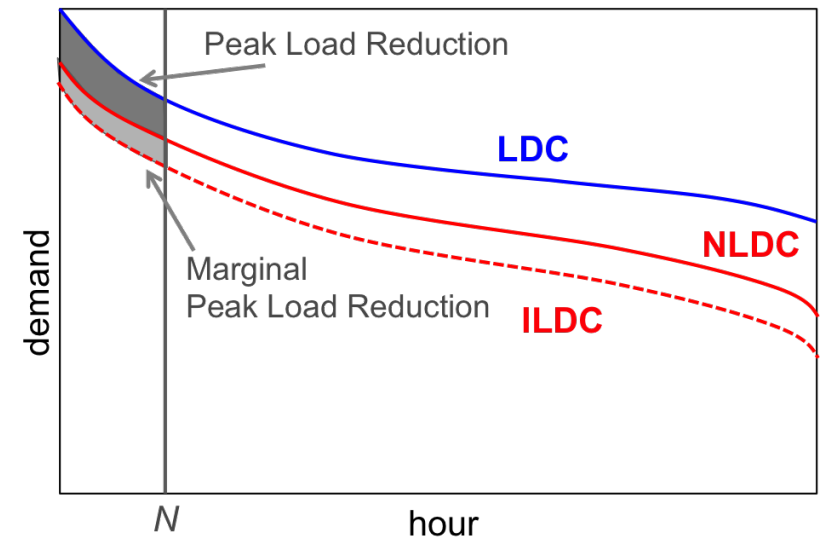

Figure 2. Conceptual depiction of the NLDC-based capacity value estimation method

flexible technologies, and the marginal capacity credits for any new units. New VG units' marginal capacity credits are computed by comparing the appropriate ILDC to the system NLDC. If additional firm capacity is needed, these marginal capacity credits influence the type, location, and amount of VG deployed. Basing these estimates on duration curves that are re-sorted for every new system condition ensures that estimated-average and marginal-capacity credits change with a changing system.

\subsection{Curtailment Estimates}

Renewable curtailment is a decision variable in RPM's co-optimization formulation that is constrained by and interactive with other variables and parameters. In RPM and in real system operations, local curtailment can be caused by transmission limits or by generator inflexibility. However, due to the reduced-order temporal representation in RPM, not all sources of curtailment are captured endogenously by the dispatch model absent additional parameters and constraints specifically designed to capture this phenomenon.

We constrain curtailment $(S)$ from technology $q$ on an hourly basis to not exceed the amount of renewable energy $(E)$ available during that hour, ${ }^{4}$ and apply a lower limit on total annual curtailment of existing resources for each NERC region $N$. The model is allowed to choose when (dispatch period $d$ and hour $h$ ) and where (node $n$ ) this curtailment occurs:

$$
\begin{aligned}
S_{d, h, n, q} & \leq E_{d, h, n, q} \\
\sum_{d, h, n}^{n \in N} S_{d, h, n, q} & \geq S_{N}^{P} \sum_{d, h, n}^{n \in N} E_{d, h, n, q}
\end{aligned}
$$

The lower limit enforces a minimum predicted curtailment rate $\left(S_{N}^{P}\right)$ expressed as a fraction of annual available energy. The curtailment rate of existing resources is estimated by applying a random forest regression ${ }^{5}$ (Breiman 2001, 2002; Fawagreh, Gaber, and Elyan 2014), populated by many RPM scenarios exported to, run, and analyzed in a production cost modeling framework with 8,760 hours, unit commitment, and DC powerflow. The random forest model is trained

\footnotetext{
${ }^{4}$ We allow curtailment of utility-scale PV, CSP without thermal energy storage, wind, and fixed-dispatch hydro (e.g., run of river facilities). We recognize that curtailment can be strongly influenced by market rules and other local factors that are not easily modeled. Therefore, our analysis and reporting does not focus on differential curtailment, for example between wind and solar; however, our methods do differentiate between technologies. Decisions about which technology to curtail in the model may be based on local congestion or other needs, but more often which technology to curtail is a degeneracy in the results, with the model choosing relatively randomly between them.

${ }^{5}$ Random forest regressions represent input-output relationships by using training data to populate multiple decision trees in which the nodes are formed by splitting the training data samples at that node into two separate groups based on one or more variable values. Output predictions are made by averaging predictions for a given input value over all trees.
} 
on key inputs, including total existing capacity by generator type, storage capacity and duration, and load in each NERC region, to model one key output: total curtailment per NERC sub-region. ${ }^{6}$

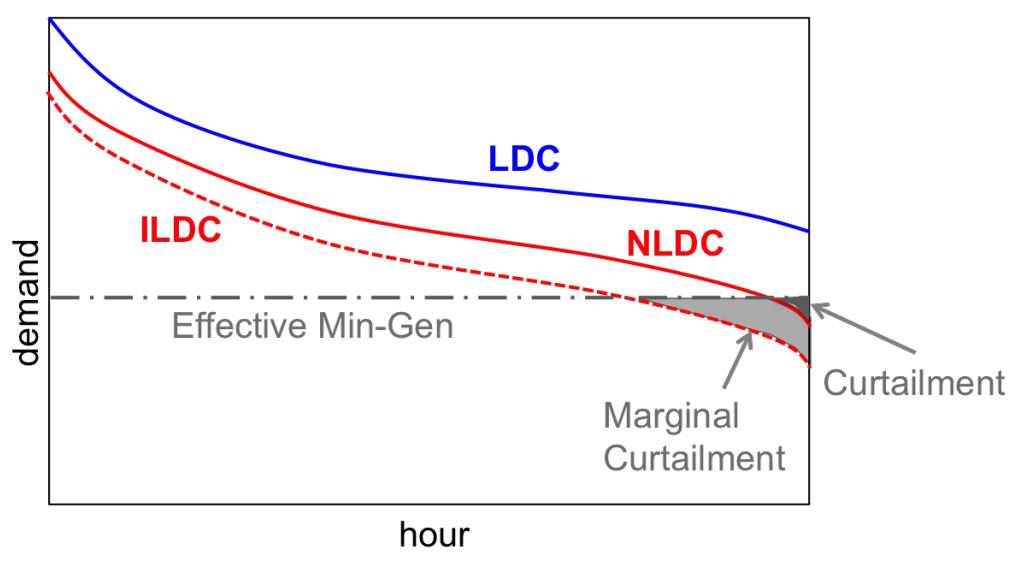

Figure 3. Conceptual depiction of the NLDC-based curtailment estimation method

We additionally model the marginal curtailment rates for new VG resources to inform investment decisions. Our method for estimating marginal curtailment of potential new renewable capacity is similar to the capacity value method in that it uses LDCs to capture the hourly variability of the system over an entire year ( 8,760 hours). However, it focuses instead on the lower tail of the curve, Figure 3, and it is complicated by the need for an effective system minimum generation level below which the system is likely to curtail energy. ${ }^{7}$ The total expected curtailment from the random forest $\left(S^{P}\right)$ is used to calculate effective minimum generation levels for each NERC region by setting the effective minimum generation level such that the existing curtailment calculated from the LDC methodology would be equivalent to the curtailment from the random forest results. The marginal curtailment rate is estimated by summing all energy between the NLDC and this minimum generation level. While the system will not necessarily only curtail energy during hours in which the NLDC falls below this effective minimum generation level, this concept allows us to estimate marginal curtailment as additional energy generated below the effective minimum generation level of the system, as well as to estimate the ability of storage to reduce curtailment, as will be discussed later.

Previously, the model assumed an incremental capacity of 500 MW was installed, and all capacity installed in the same model year received the same curtailment fraction (Hale et al. 2016). The new methodology includes a piecewise adjustment with increasing marginal curtailment rates for seven pre-determined installed capacity bands. This new constraint leads to less solar being installed, and to solar being installed in a more distributed manner. Figure 4 shows an example of the increasing curtailment rates for wind and solar in the model. The marginal curtailment values are adjusted each year for each region and technology, accounting for the changing mix of renewable generation in that region.

RPM enforces marginal curtailment $\left(S^{N}\right)$ separately for each resource region $r$ and technology $q$, for each piecewise band $s$ :

$$
\sum_{d, h, n, q}^{n \in r} S_{d, h, n, q, s}^{N} \geq S_{r, q, s}^{P} \sum_{d, h, q} E_{d, h, r, q}
$$

The piecewise marginal curtailment fraction contributes to the model's decision of where to build additional resources, because locations with higher marginal curtailment levels will be able to provide less energy per unit of capacity, and

\footnotetext{
${ }^{6}$ The random forest includes information about the existing system only. There are therefore some potential errors if large quantities of new capacity of different technology types are installed in a given year; however this error tends to be small.

${ }^{7}$ The minimum generation capabilities of a system are influenced by the flexibility of the system, including physical minimum generation levels, commitment statuses of generators, transmission congestion, and ramping capabilities. The duration curve-based method does not contain commitment decisions, and so is unable to fully capture the actual minimum generation capability of a system.
} 
therefore will be less valuable-all other variables being equal-than regions with lower marginal curtailment rates.

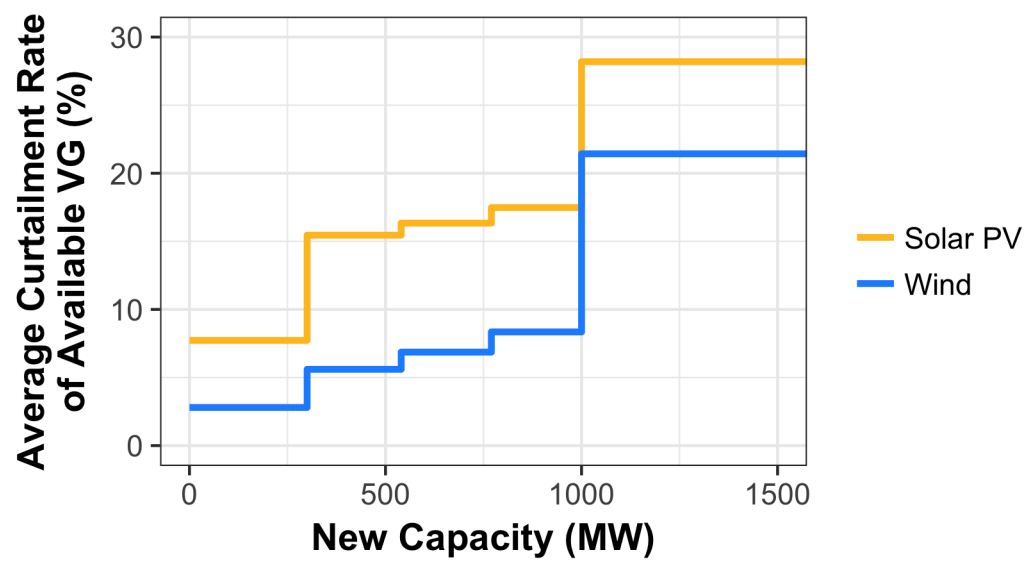

Figure 4. Example wind and solar marginal curtailment, taken as the average values across all regions. The figure demonstrates installed capacity up to $1500 \mathrm{MW}$. As the installed capacity increases, the marginal curtailment rate also increases, thus penalizing simultaneous installation of a large amount of one resource in the same region.

This report is available at no cost from the National Renewable Energy Laboratory at www.nrel.gov/publications. 


\section{Modeling Flexible Technologies}

To model flexible energy storage technologies in RPM, an important but difficult characteristic to account for is their energy-constrained nature. PHES, BES, and CSP with TES must have sufficient energy in reserve to provide any grid service, whether that be generation or an ancillary service; to shift grid energy that would otherwise be curtailed, a pumped hydro plant must have unfilled capacity in its reservoir, and batteries cannot be fully charged. If a CSP with TES plant has a full thermal reservoir, any additional energy that could be collected must instead be spilled. In other words, to represent energy-constrained technologies, one needs to continually account for the current state of the energy reservoir. Given that RPM does not model all hours of the year, these considerations factor into the external 8,760 calculations that determine capacity value and curtailment effects, as well as the reduced order dispatch embedded in the optimization model.

\subsection{Grid Storage Dispatch}

In the optimization model, PHES and BES are characterized by a duration defined by the energy capacity ( $e$ in $\mathrm{MWh} / \mathrm{MW}$ ) and power capacity ( $C$ in MW), a roundtrip efficiency $(\eta)$, and a time-varying storage level $(L)$. Storage level is modeled by letting RPM choose a starting storage level $L_{d}^{\text {start }}$ for each dispatch period $d$, and then calculating changes to the level within the dispatch period based on generation $P^{\mathrm{gen}}$, charging $P^{\mathrm{chg}}$, and use for flexibility and regulation reserves ( $R^{\text {flex }}$ and $R^{\text {reg }}$, respectively):

$$
\begin{aligned}
& L_{d, 0}=L_{d}^{\mathrm{start}} \\
& L_{d, h}=L_{d, h-1}-P_{d, h}^{\mathrm{gen}}+\eta \cdot P_{d, h}^{\mathrm{chg}}-0.25\left(R_{d, h}^{\mathrm{flex}}+R_{d, h}^{\mathrm{reg}}\right)(1-\eta)
\end{aligned}
$$

where each operational variable is indexed by the model hour $(d, h)$. While incorporating a binary variable to ensure no charging and discharging occur simultaneously may be beneficial (Xu et al. 2018), we have found that this only occurs in limited instances within RPM and is more of a concern for operation-focused models. The storage level $L_{d, h}$ must always be less than the total energy capacity $e \cdot C$, and the total dispatch is limited by the power capacity:

$$
P_{d, h}^{\mathrm{gen}}+P_{d, h}^{\mathrm{chg}}+R_{d, h}^{\mathrm{spin}}+R_{d, h}^{\mathrm{flex}}+R_{d, h}^{\mathrm{reg}} \leq C
$$

The provision of spinning reserves from a storage technology does not actively deplete the storage reservoir; however, the amount of spinning reserves provided in each hour, $R_{d, h}^{\text {spin }}$, is limited by the amount of energy available, $L_{d, h}$. The use of storage to provide flexibility and regulation reserves results in a partial need to recharge the resource due to the assumption that these signals will be energy neutral, thereby leaving a deficit proportional to one minus the roundtrip efficiency. The proportionality constant of 0.25 was chosen based on the multiplication of two factors, with one factor of 0.5 representing energy-neutrality and another factor of 0.5 representing a uniform distribution of actual dispatch between $0 \mathrm{MW}$ and the amount of capacity committed to that service. For example, on average, a $100 \mathrm{MW}$ storage facility providing one hour of flexibility or regulation reserves would spend half of its time charging and half discharging, and would on average be operating at $50 \mathrm{MW}$, resulting in a change in level of $-50 \mathrm{MW} \cdot 0.5 h+\eta$. $50 \mathrm{MW} \cdot 0.5 h=-0.25 \cdot 100 \mathrm{MWh} \cdot(1-\eta)$.

Starting storage levels are then related to each other via a temporal transition matrix (Tejada-Arango et al. 2018) and an accounting of how much charge is accumulated or dissipated over each dispatch period. The transition matrix $T$ has elements $T_{d, d^{\prime}}$ that represent the fraction of time in dispatch period $d$ for which the next different dispatch period is $d^{\prime}{ }^{8}$ Accumulation per dispatch period,

$$
A_{d}=L_{d, h^{\text {final }}}-L_{d}^{\text {start }}
$$

is required to sum to zero over the year, mitigated by the scaling factor $s_{d}$ that equals the number of hours represented by each dispatch period $d$ :

$$
\sum_{d} s_{d} \cdot A_{d}=0 .
$$

\footnotetext{
${ }^{8}$ Thus $T_{d, d}=0$ and $\sum_{d^{\prime}} T_{d, d^{\prime}}=1.0$.
} 
These factors are then brought together to relate the starting storage levels for each dispatch period to each other:

$$
L_{d}^{\text {start }}=L^{\text {ref }}+\sum_{d^{\prime}} T_{d^{\prime}, d} \cdot s_{d^{\prime}} \cdot A_{d^{\prime}}
$$

The reference storage level $L^{\text {ref }}$ and each $L_{d}^{\text {start }}$ are constrained to be between zero and the energy capacity $e \cdot C$, which ensures that the energy capacity of the resource is respected over seasonal, in addition to hourly, timescales. Thus energy imbalances within a dispatch period are allowed, but these are limited to physically possible quantities; and charging in one period is able to reduce peak demand in another, but only to the extent encoded in the transition matrix. For example, in the model described below we have:

$$
\begin{gathered}
T=\begin{array}{l}
\text { low } \\
\text { mid } \\
\text { high } \\
\text { peak }
\end{array}\left(\begin{array}{cccc}
0 & \text { mid } & \text { high } & \text { peak } \\
0.69 & 0 & 0 & 0 \\
0 & 0.15 & 0 & 0.85 \\
0 & 0 & 1 & 0
\end{array}\right) \\
s=\left(\begin{array}{llll}
260 & 91 & 13 & 1
\end{array}\right) .
\end{gathered}
$$

Combining these parameters with Equation 3.6 applied to the low dispatch period yields

$$
-L^{\mathrm{ref}} \leq 0.69 \cdot 91 \cdot A_{\mathrm{mid}} \leq e \cdot C-L^{\mathrm{ref}}
$$

that is, mid dispatch period accumulations $\left(A_{\text {mid }}\right)$ or reductions $\left(-A_{\text {mid }}\right)$ of stored energy are limited to at most $1 /(0.69 \cdot 91)=1.6 \%$ of energy capacity $(e \cdot C)$ per representative day. The remaining $98.4 \%$ of energy capacity is available, but only for use within the representative day and subject to starting level $L_{\text {mid }}^{\text {start }}$. Ignoring these transitions would undervalue the potential contributions of flexible technologies, particularly those with longer storage durations, such as PHES. ${ }^{9}$

\subsection{CSP with TES Dispatch}

The dispatch model for CSP with TES is similar to that for grid storage. The main difference is that CSP plants are charged from solar thermal energy instead of from the grid such that there us no particular loss associated with charging $(\eta=1)$, but there is energy dissipation and the possibility of spillage. Also, charging drops out of Equation 3.3. Specifically, Equation 3.2 and Equation 3.3 become

$$
\begin{aligned}
& L_{d, h}=L_{d, h-1}(1-\alpha)-P_{d, h}^{\mathrm{gen}}-P_{d, h}^{\mathrm{spill}}+P_{d, h}^{\mathrm{chg}} \\
& P_{d, h}^{\mathrm{gen}}+R_{d, h}^{\mathrm{spin}}+R_{d, h}^{\mathrm{flex}}+R_{d, h}^{\mathrm{reg}} \leq C,
\end{aligned}
$$

where $\alpha$ is an energy dissipation constant representing the fraction of stored energy that dissipates over the course of an hour (assumed equal to 0.0006 (Pacheco et al. 2002)), and $P_{d, h}^{\text {spill }}$ is the amount of energy that must be spilled because there is not sufficient room for it in the storage reservoir. Spillage (like curtailment) does not have an explicit cost in the model, only the opportunity cost of not using the energy. Spinning reserves are still limited by energy capacity. In addition, RPM's limits on reserves provided by linearly dispatched plants apply: $R_{d, h}^{\text {reg,flex,spin }} \leq P_{d, h}^{\text {gen }}$; that is, reserves can only be provided when the power block is also generating.

RPM models the energy collected by CSP plants from the electricity point of view; that is, the profiles used to charge storage already account for the losses experienced when converting from thermal to electric energy. This is done by modeling a prototypical plant in the System Advisor Model (SAM) ${ }^{10}$ that accounts for heat exchanger and power

\footnotetext{
${ }^{9}$ While the methods described here could be used to model PHES investment decisions, only existing PHES was included in this analysis.

${ }^{10} \mathrm{https} / / / \mathrm{sam} . n$ rel.gov/
} 
block efficiencies. One key parameter in CSP plant design is the solar multiple (SM), which is defined as the rated thermal power of the solar field converted to its electricity equivalent and then divided by the power capacity of the steam turbine. In RPM, we model a discrete set of CSP with TES configurations, designated by solar multiple SM and energy capacity $e$. Given a particular CSP with TES configuration, we then build up the charging profile using a representative profile of hourly capacity factors from SAM for a SM 1 plant ( $\left.p_{d, h}^{\mathrm{CSP}}\right)$, the plant capacity $C$, and the solar multiple SM associated with the selected configuration:

$$
P_{d, h}^{\mathrm{chg}}=\mathrm{SM} \cdot \mathrm{C} \cdot p_{d, h}^{\mathrm{CSP}}
$$

This energy must then be allocated to generation or storage. If there is insufficient storage capacity a portion of the collected energy may also be spilled.

\subsection{Grid Storage Capacity Value and Curtailment Reductions}

As for VG, we estimate the impact of flexible technologies at peak and minimum net-load times in the 8760 portion of the RPM model through the estimation of capacity value and curtailment impacts. For grid charged storage, these quantities are estimated by computing a heuristic dispatch profile for the year for each configuration under consideration. The purpose of this dispatch profile is not to accurately represent operational conditions, but to maximize capacity value and absorption of energy that would otherwise be curtailed, under the assumption that we want to give each technology full credit for its capabilities to provide these high-value services while maintaining reasonable foresight.

The heuristic algorithm thus seeks to charge during periods of low net demand and discharge during peak net-load hours, all while ensuring that the constraints on the energy level are respected (Figure 5). This heuristic algorithm looks ahead 24 hours and attempts to 1) reduce peak net-load during as many above-threshold hours as possible and 2 ) increase load below the effective minimum generation line to eliminate as much curtailment as possible. A cycle period of 24 hours is assumed because the dispatch of these non-seasonal technologies is expected to roughly balance over the course of the day, especially in the high solar resource region studied below.

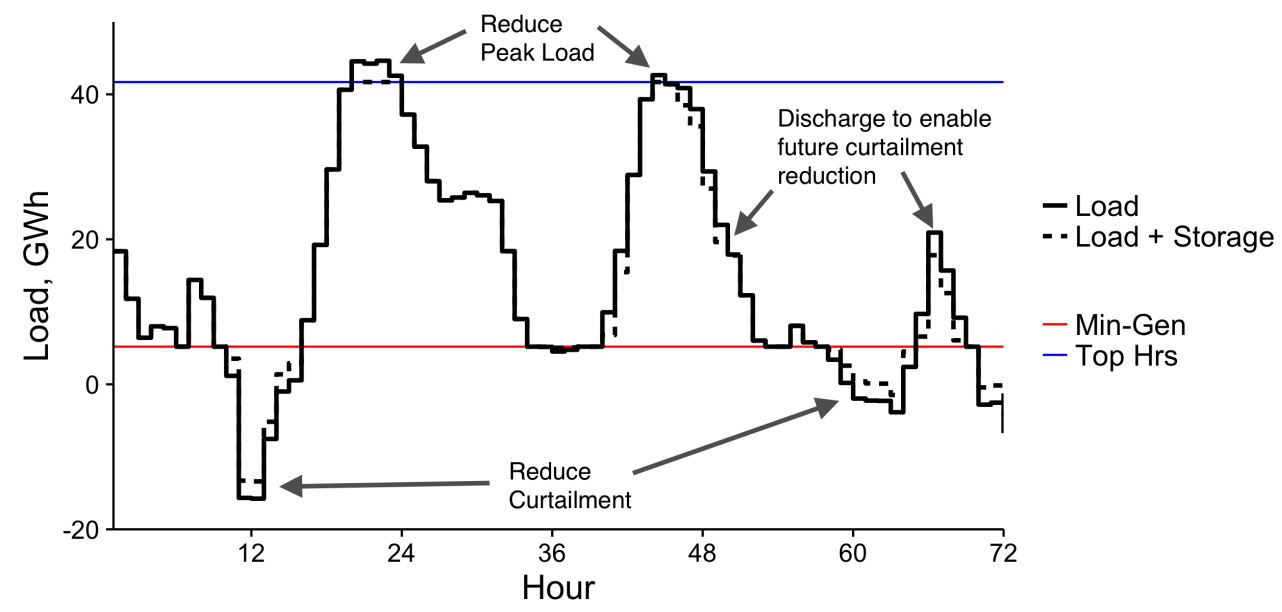

Figure 5. Dispatch heuristic for battery storage. A 24-hour look-ahead period enables precharging or discharging to maximize the capacity value and curtailment reduction. A similar heuristic is used for CSP with TES; however, charging only occurs from the solar array.

The profiles created by this heuristic are used similarly to the NLDC and ILDCs in Figure 2 to calculate the capacity credit of each technology based on the top 100 net-load hours of the year, and to calculate the expected reduction of VG curtailment based on the change in net-load that falls below the effective minimum generation level. The resulting parameters are defined per technology sub-class and NERC sub-region. The methodology provides a curtailment reduction fraction for existing storage and a marginal curtailment reduction factor for new storage, which are enforced 
as both curtailment reductions and minimum charging amounts in the dispatch model. Both new and existing storage are only able to reduce curtailment from existing VG-we do not model the ability of new storage to reduce curtailment required of new VG installations due to inherent non-linearities in that relationship. ${ }^{11}$

\subsection{CSP with TES Capacity Value and Spillage}

The capacity value and curtailment impacts of CSP with TES are also estimated by computing heuristic dispatch profiles in the 8760 portion of RPM. As in the dispatch model, many aspects are similar to the methods applied to grid charged storage, but the charging profile is fixed to the output of the solar field. Thus, CSP with TES plants cannot reduce the amount of VG curtailment experienced by the system as a whole but sometimes have to add to that curtailment because their storage reservoirs are full, and yet they are collecting more energy than either their power block or the power system can take at the moment. Because for CSP this loss of energy is achieved via thermal dissipation rather than dialing back real power output, we often refer to CSP "spillage" rather than "curtailment."

Under the heuristic dispatch, the CSP facility will preferentially generate or discharge its storage during peak net-load hours (defined as those hours above the "top hours threshold"). For all hours when the net-load is below the effective minimum generation level (Min-Gen), the CSP facility will preferentially store energy as much as possible to avoid increasing curtailment. Any time the storage facility is full and the plant is generating at maximum capacity, excess production from the solar field is counted as spillage. The capacity value and spillage are both calculated for each technology class and CSP resource region.

\footnotetext{
${ }^{11}$ This is a topic of ongoing research on coupling technologies to enable capturing their co-benefits within a linearized model.
} 


\section{Technology and Scenario Definitions}

\subsection{Technology Configurations}

The 8760 methods for new BES and CSP with TES are applied to discrete configurations characterized by hours of storage (BES and CSP with TES) and solar multiple (CSP with TES only). As such, particular configurations must be specified. These are chosen by applying pricetaker analyses to RPM runs as a post-processing step. For both BES and CSP with TES, the pricetaker analysis chooses the configuration that is able to maximize net revenue calculated from an hourly dispatch model, grid service prices from RPM, and technology costs assembled from major components. The post-processing step runs this analysis for each allowable model location in each model year using the capacity, energy, and ancillary services prices output by RPM. Because RPM only provides energy and ancillary service prices for a select number of hours in the year, these are distributed to the remaining hours using RPM's mapping from each hour of the year $t$ to one of the represented hours $d, h$. Key features of the pricetaker models are summarized in Appendix C.

The technology cost components for BES are energy capacity $(\$ / \mathrm{kWh})$ and balance of system costs $(\$ / \mathrm{kW})$. CSP with TES cost components are the power block $(\$ / \mathrm{kW}-\mathrm{e})$, a solar field $(\$ / \mathrm{kW}$-e at SM 1$)$, and thermal storage $(\$ / \mathrm{kWh}-\mathrm{e})$, where the suffix '-e' refers to electric-equivalent energy (as opposed to thermal). The costs for these components were taken from the 2018 NREL ATB (NREL 2018) for BES, and from Murphy et al. (2019) for CSP with TES. In RPM and the pricetaker analyses, the overall capital cost for a configuration is calculated based on the hours of storage $(e)$ for BES:

$$
\text { Capital Cost }(\$ / \mathrm{kW})=\text { Balance of System }(\$ / \mathrm{kW})+e \cdot \text { Energy Capacity }(\$ / \mathrm{kWh})
$$

and based on both the solar multiple (SM, used to scale the reference, $\mathrm{SM}=1$, solar field $\operatorname{costs}^{12}$ ) and the hours of storage $(e)$ for CSP with TES:

$$
\begin{gathered}
\text { Solar Field }(\$ / \mathrm{kW}-\mathrm{e})=\text { Ref. Solar Field }(\$ / \mathrm{kW}-\mathrm{e}, \mathrm{SM}=1) \cdot \frac{(\$ 1700 \cdot \mathrm{SM}+\$ 419)}{\$ 1700+\$ 419 / 2.4} \\
\text { Capital Cost }(\$ / \mathrm{kW}-\mathrm{e})=\text { Power Block }(\$ / \mathrm{kW}-\mathrm{e})+\text { Solar Field }(\$ / \mathrm{kW}-\mathrm{e})+e \cdot \mathrm{TES}(\$ / \mathrm{kWh}-\mathrm{e}) .
\end{gathered}
$$

In addition to determining capital cost, these configuration parameters implicitly determine which services the plant will be able to provide. Both RPM and the pricetaker optimization formulations use least cost models to determine the best trade-off. Higher energy capacities enhance both of these technologies' abilities to provide firm capacity and energy-shifting from low-value to high-value hours. The optimal balance depends on system conditions as well as component costs.

The results of the pricetaker analyses for this study are shown in Figure 6. By solving the resulting optimization problems for every combination of BES build location and CSP resource region and RPM model year, we get many optimal plant configurations; however, in some locations and years these optimal configurations are still not economically advantageous to build. Figure 6 shows optimal configurations screened so that their net value is greater than zero. Five of the configuration options for BES and all five of the CSP with TES configurations presented to RPM in the results below are indicated. In addition, RPM is given the option to build $0.5 \mathrm{~h} \mathrm{BES}$, which it exercises in 2020 to fulfill its California energy storage mandate obligations.

\subsection{Scenario Framework}

In the analysis, we examine the impact of including BES and CSP with TES as investment options across three different scenarios in a region of the desert southwestern United States defined by the balancing authorities Southern California Edison (SCE), Nevada Power (NEVP), and Western Area Power Administration Lower Colorado (WALC). Additional information on the regional model is available in Appendix A. The three scenarios we evaluate are:

- Base consists of RPM default, mid-line assumptions for fuel prices (EIA 2017), technology costs (NREL 2017), and policy.

\footnotetext{
${ }^{12}$ The solar field costs are modeled as consisting of one part that scales only with power block capacity, while the majority scales with solar field size and is thus proportional to the solar multiple.
} 

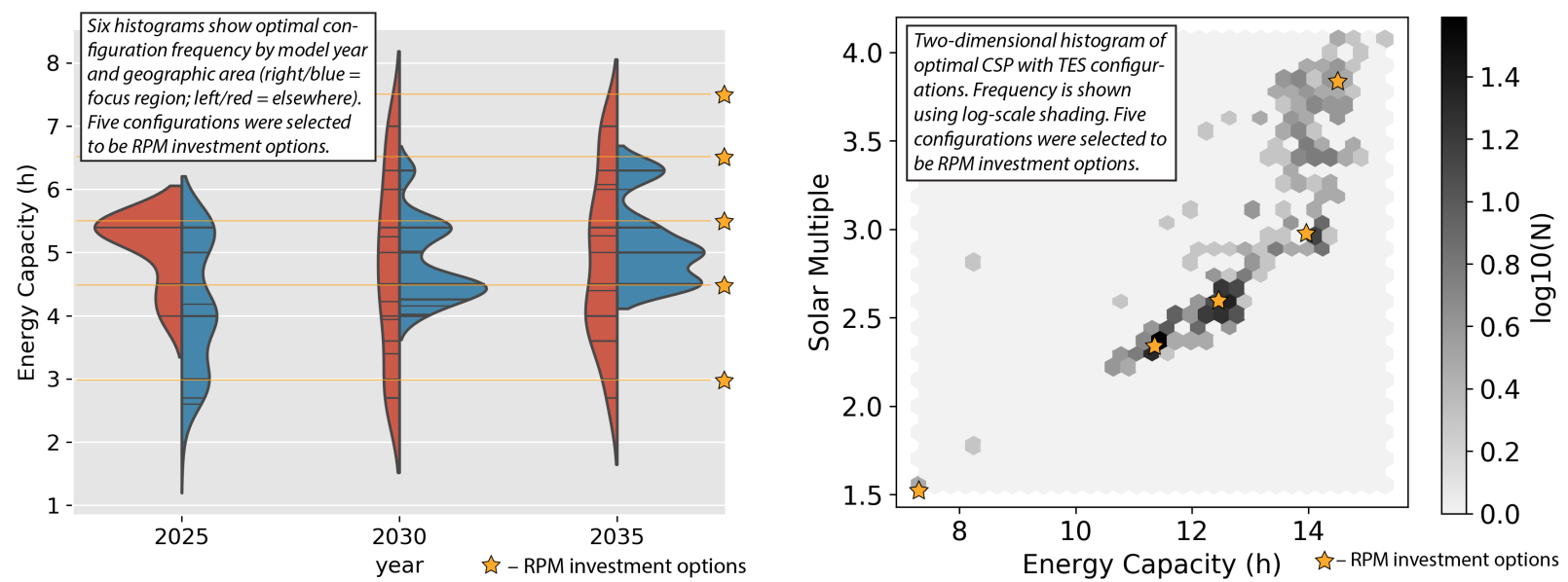

Figure 6. Optimal (a) BES and (b) CSP with TES configurations computed from a set of RPM scenarios and filtered down to those with positive net value. Configurations subsequently modeled as investment options in RPM are marked with stars.

- Low Cost Tech (LCT) overlays the Base conditions with low technology cost profiles for solar photovoltaics (PV), battery storage, and CSP with TES.

- High Cost Fuel and Low Cost CSP (HCF\&CSP) overlays the Base conditions with a high natural gas price trajectory and a carbon price trajectory ${ }^{13}$ as well as CSP capital costs from Murphy et al. (2019).

For each scenario, we simulate the scenario two ways: 1) assuming BES and CSP with TES are not available, and 2) assuming BES and CSP with TES are available. We explore how their inclusion impacts the least-cost 2030 system capacity build-outs, energy and reserves dispatch, and model service prices.
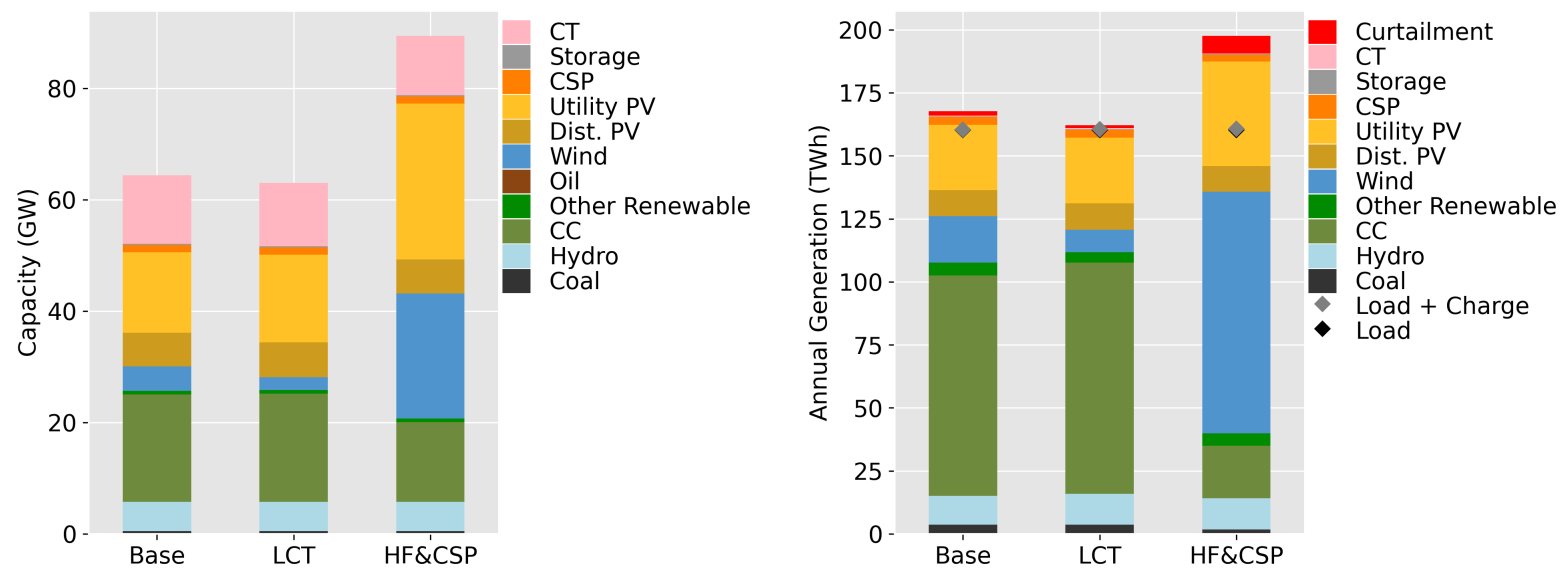

Figure 7. Focus region 2030 (left) capacity and (right) dispatch without BES and CSP with TES investment options

Figure 7 depicts the RPM model projections of 2030 focus region capacity and annual generation for these scenarios under the assumption of no BES or CSP with TES investment. Designed to meet a peak load of $33.4 \mathrm{GW}$, the Base system is comprised predominantly of natural gas combined cycle (CC), natural gas combustion turbine (CT), and solar units (including existing CSP), with significant contributions from hydro and wind. With regards to imports

\footnotetext{
${ }^{13}$ Trajectory composed by taking the 75 th percentile of the non-zero carbon price trajectories in https://resourceplanning.lbl.gov in 2017 and is reproduced in the appendix.
} 
and exports, the Base system is a net exporter of $4.6 \mathrm{TWh}$, compared to a total annual load of $160 \mathrm{TWh}$. Absent BES and CSP with TES investment options, the LCT scenario deploys significantly more PV throughout the Western Interconnection, but within the focus region the increase in PV capacity is more than offset by reductions in wind and CT capacity. On the generation side, the reduction in wind generation is offset by increased CC generation and imports. The region becomes a net importer of $0.5 \mathrm{TWh}$. The HCF\&CSP scenario drives significantly more change within the focus region, leading to large increases in PV $(13.6 \mathrm{GW})$ and wind $(18.0 \mathrm{GW})$ capacity at the expense of some CC $(4.9 \mathrm{GW})$ and CT $(1.6 \mathrm{GW})$ capacity. The region becomes a major exporter of renewable energy-on net exporting $23.5 \mathrm{TWh}$ per year. 


\section{Results}

In all three scenarios, including flexible resource investment options changes the least-cost system composition for the focus region in 2030 (Figure 8).

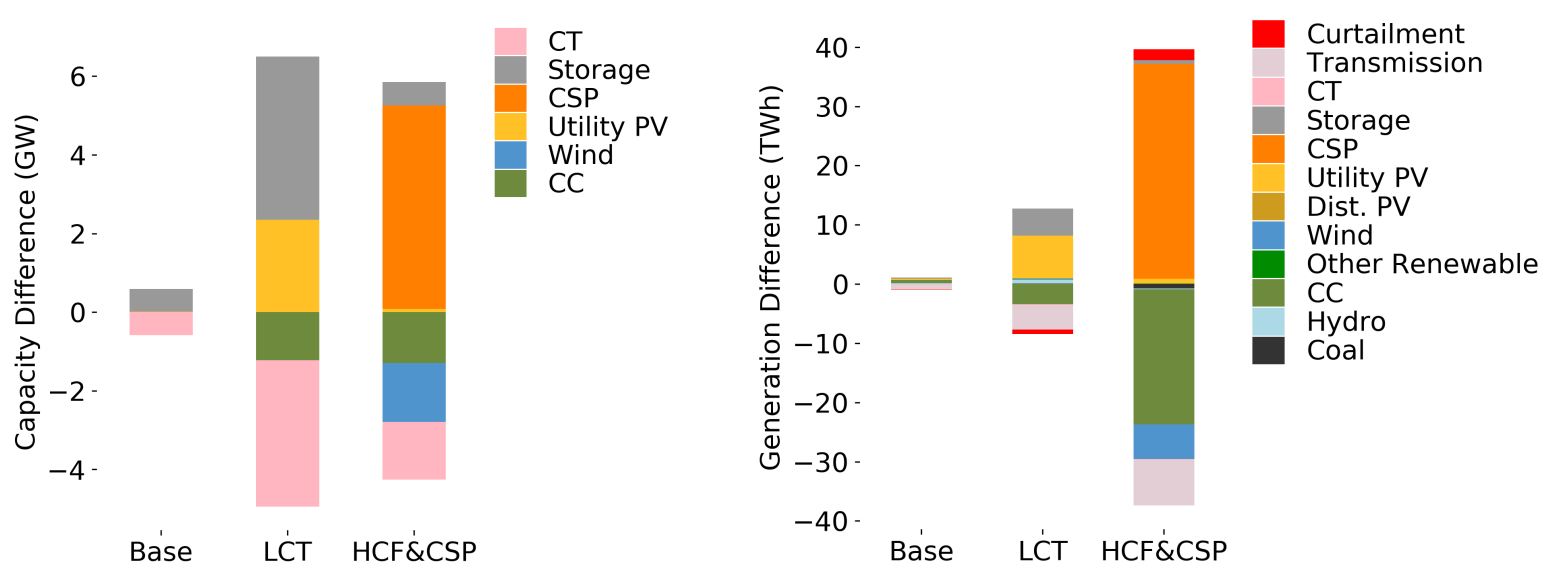

Figure 8. Focus region differences in 2030 (left) capacity and (right) dispatch when flexible investment options for BES and CSP with TES are enabled. Differences are computed relative to analogous scenarios with the same underlying conditions but no option to invest in BES or CSP.

In the Base scenario, the impact is modest but measurable (less than $1 \%$ of capacity and dispatch). When flexibility investment options are not modeled, RPM does not capture the impact of California's storage mandate of 1,325 MW by 2025 , including $580 \mathrm{MW}$ of BES capacity required for SCE. When this impact is directly captured, we see a near direct swap of BES capacity for CT capacity in the focus region, and the trend of building short-duration $(0.5 \mathrm{~h})$ storage in 2020 but longer-duration ( $3 \mathrm{~h}$ ) storage capacity in 2030.

The capacity and generation differences for the LCT and HCF\&CSP scenarios are much less subtle. With mid fuel costs but low cost PV and BES, having a planning tool that captures the potential benefits of BES yields a lower cost plan that uses new BES capacity to deploy more PV and fewer natural gas CT and CC units. The resulting system generates less from CCs while overall exporting more electricity from this solar-resource rich region. Similarly, enabling the model to invest in CSP with TES under HCF\&CSP conditions leads to a plan with less CC, CT, and wind capacity, in favor of about $5 \mathrm{GW}$ of new CSP capacity with SM 3.8 and 14.4 hours of storage. ${ }^{14}$

Consistent with the large quantity of CSP generation shown in Figure 8, Figure 9 confirms that the CSP capacity built in the HCF\&CSP scenario operates mostly as a baseload, with some spillage during morning hours of low load periods ${ }^{15}$ and an emphasis on running full out during evening hours. What is inherent in the model but not obviously conveyed by the plot is the degree to which RPM captures shifting of energy between the dispatch periods. Table 1 and Table 2 document the energy transfers between dispatch periods for the CSP and the BES resources whose dispatch is depicted. The tables break down the components that link the starting storage levels for each dispatch period into Accumulation $\left(A_{d}\right)$, Scaled Accumulation $\left(s_{d} \cdot A_{d}\right)$, Transfer To $\left(\sum_{d^{\prime}} T_{d^{\prime}, d} \cdot s_{d^{\prime}} \cdot A_{d^{\prime}}\right)$, Net Transfer To $\left(\left(\sum_{d^{\prime}} T_{d^{\prime}, d} \cdot s_{d^{\prime}} \cdot A_{d^{\prime}}\right)-s_{d} \cdot A_{d}\right)$, and Starting Storage Level $\left(L^{\mathrm{ref}}+\sum_{d^{\prime}} T_{d^{\prime}, d} \cdot s_{d^{\prime}} \cdot A_{d^{\prime}}\right)$. This analysis shows that all dispatch periods, and the relationships between them, respect the overall storage capacities of the resources.

These results also illuminate some of the differences between BES and CSP with TES. For example, in this scenario year BES is dispatched to shift as much energy as possible to the peak day, but on the whole CSP shifts energy from

\footnotetext{
${ }^{14}$ Configuration selected from the five indicated in Figure 6.

${ }^{15}$ The opportunity cost of spillage may not be sufficient to justify additional investment in TES capacity. Because RPM does not co-optimize CSP configurations, it is not clear if that is the case here; however, we do see that RPM found it worthwhile to build CSP with TES even though not all of the available energy could be used.
} 

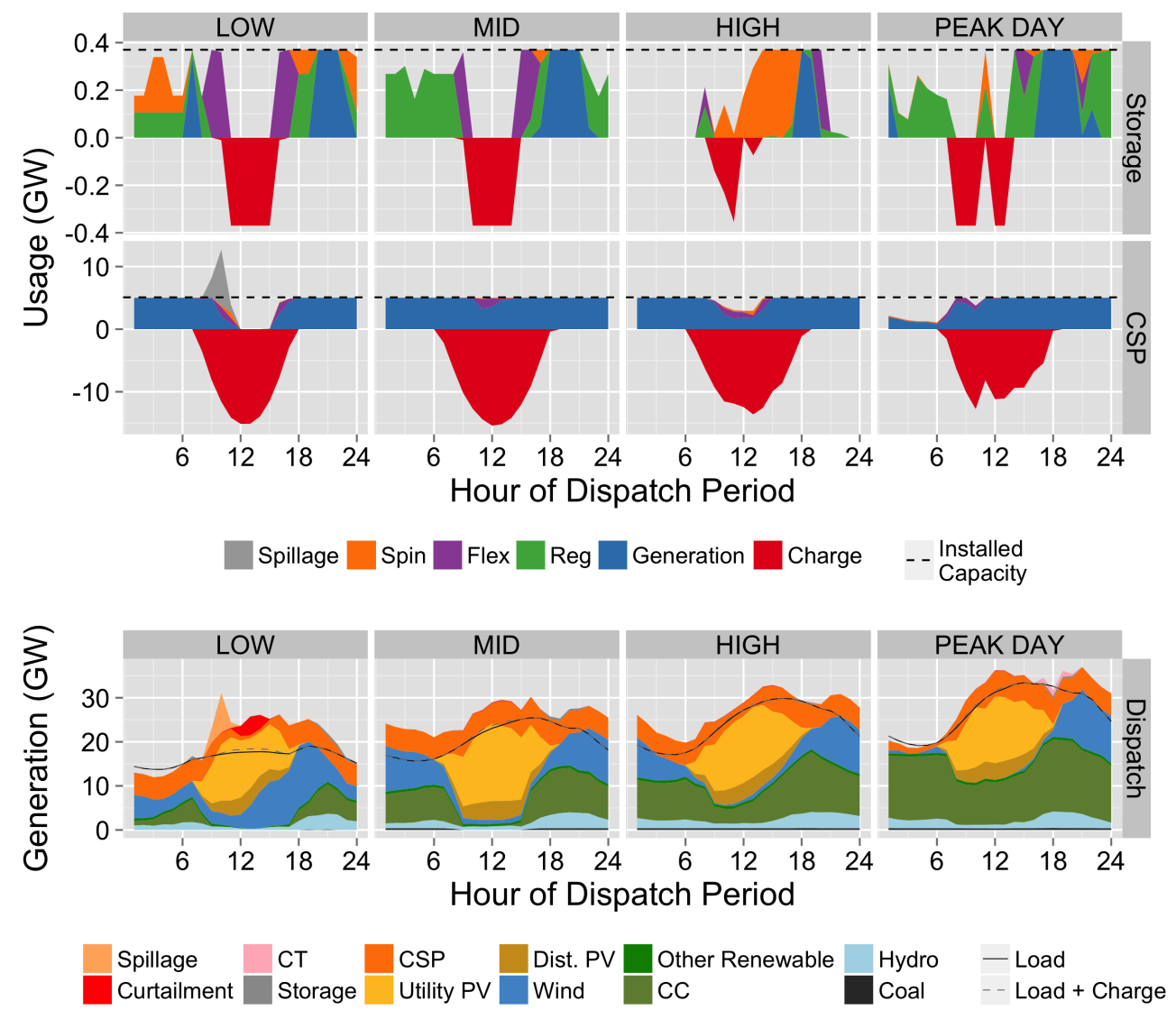

Figure 9. HCF\&CSP focus region dispatch in 2030 for (top) all services from 4.5h BES and CSP with TES, and (bottom) total system generation

Table 1. Storage accumulations, transfers, and starting storage levels per dispatch period for the CSP with TES SM 3.8, 14.4 $\mathrm{h} 2030$ builds in the focus region. These data analyze 11 individual plants as one 5,089 MW, 73,282 MWh resource.

\begin{tabular}{rrrrr}
\hline Storage (MWh) & \multicolumn{1}{c}{ Low } & \multicolumn{1}{c}{ Mid } & \multicolumn{1}{c}{ High } & Peak Day \\
\hline Accumulation & 37 & 141 & -667 & 881 \\
Scaled Accumulation & 8,936 & 12,864 & $-22,680$ & 881 \\
Transfer To & 8,906 & 5,600 & 4,839 & $-19,345$ \\
Net Transfer To & -30 & $-7,263$ & 27,520 & $-20,226$ \\
Starting Storage Level & 36,379 & 33,073 & 32,312 & 8,128 \\
\hline Storage (\%) & Low & \multicolumn{1}{c}{ Mid } & High & Peak Day \\
\hline Scaled Accumulation & $12 \%$ & $18 \%$ & $-31 \%$ & $1 \%$ \\
Transfer To & $12 \%$ & $8 \%$ & $7 \%$ & $-26 \%$ \\
Net Transfer To & $0 \%$ & $-10 \%$ & $38 \%$ & $-28 \%$ \\
Starting Storage Level & $50 \%$ & $45 \%$ & $44 \%$ & $11 \%$ \\
\hline
\end{tabular}

This report is available at no cost from the National Renewable Energy Laboratory at www.nrel.gov/publications. 
Table 2. Storage accumulations, transfers, and starting storage levels per dispatch period for the BES $4.5 \mathrm{~h}$ capacity in the focus region in 2030 . These data analyze three individual plants as one $370 \mathrm{MW}, 1,665 \mathrm{MWh}$ resource.

\begin{tabular}{rrrrr}
\hline Storage (MWh) & Low & Mid & High & Peak Day \\
\hline Accumulation & -1 & 3 & 3 & -250 \\
Scaled Accumulation & -129 & 283 & 96 & -250 \\
Transfer To & 196 & -115 & -162 & 82 \\
Net Transfer To & 325 & -398 & -258 & 331 \\
Starting Storage Level & 364 & 53 & 6 & 250 \\
\hline Storage (\%) & Low & Mid & High & Peak Day \\
\hline Scaled Accumulation Over & $-8 \%$ & $17 \%$ & $6 \%$ & $-15 \%$ \\
Transfer To & $12 \%$ & $-7 \%$ & $-10 \%$ & $5 \%$ \\
Net Transfer To & $20 \%$ & $-24 \%$ & $-16 \%$ & $20 \%$ \\
Starting Storage Level & $22 \%$ & $3 \%$ & $0 \%$ & $15 \%$ \\
\hline
\end{tabular}

the peak day to the high dispatch period. On the peak day there is significant solar resource, enabling CSP to operate as a base-load resource while also storing energy for future days. This, and the fact that the eleven individual resources whose results are aggregated in Table 1 do not have identical shifting patterns in terms of which dispatch periods contribute energy to which other dispatch periods, demonstrates that optimal CSP TES dispatch is influenced by solar variability as well as demand levels.

Enabling investment in flexible technologies also has a large impact on reserve provision. RPM models three types of reserves: spinning contingency, regulation (load balancing), and flexibility reserves; only models up-reserves; and assumes that curtailed renewable energy will be able to provide reserves by 2030 . When flexible investment options are enabled, all three types of reserves are impacted (Figure 10). BES in particular stands out as providing a significant proportion of the required regulation reserves in all three scenarios. While fewer regulation reserves are required than spinning and flexibility reserves, restrictions on which generators are able to provide these reserves are tighter. As such, fast-reacting batteries can be leveraged with high impact to provide this reserve product. This in turn lowers reserve prices, even in the Base scenario where otherwise the impacts of co-optimizing flexible technologies is modest (Figure 11). 


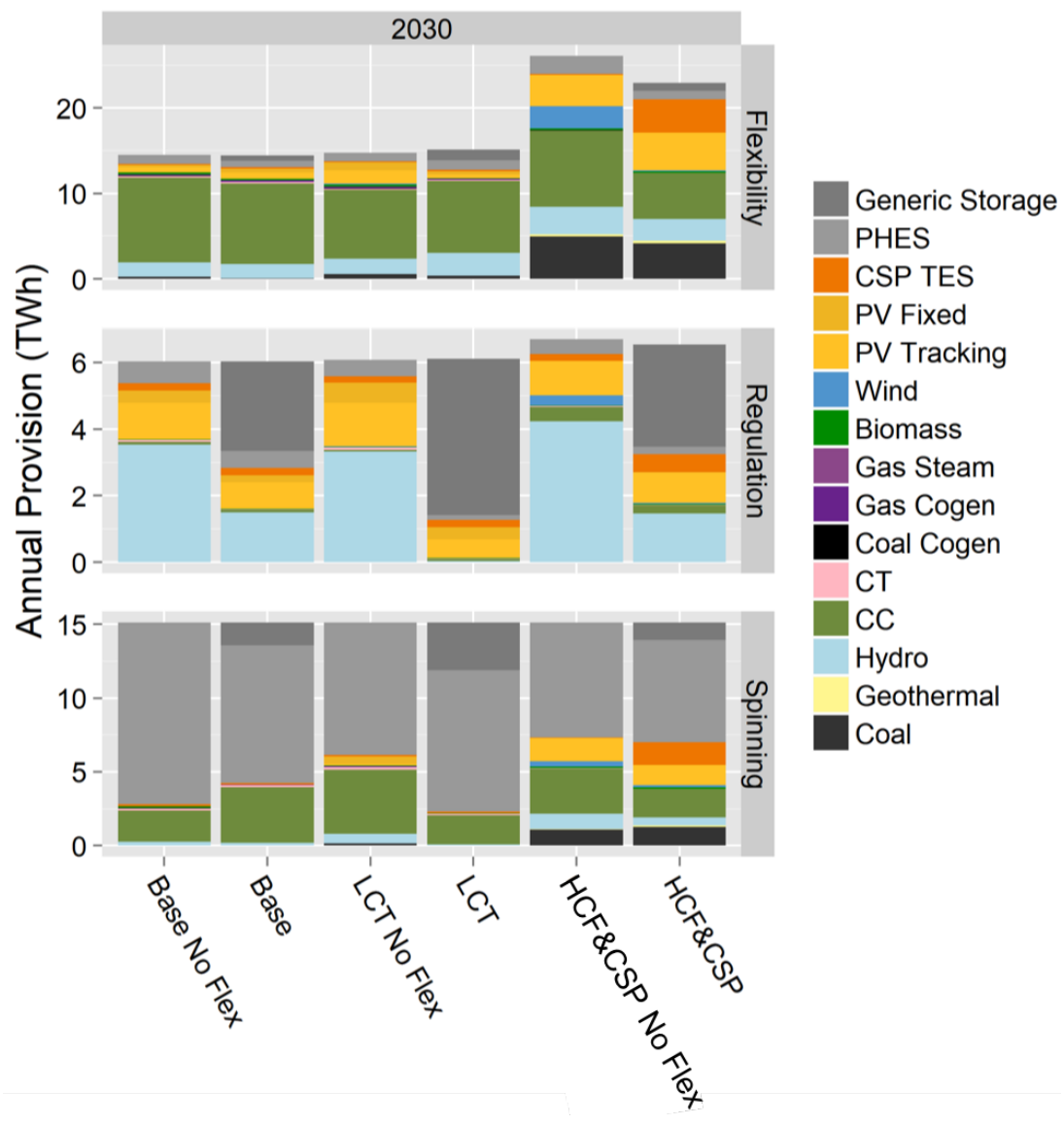

Figure 10. Reserves provided by technology in 2030 for all scenarios

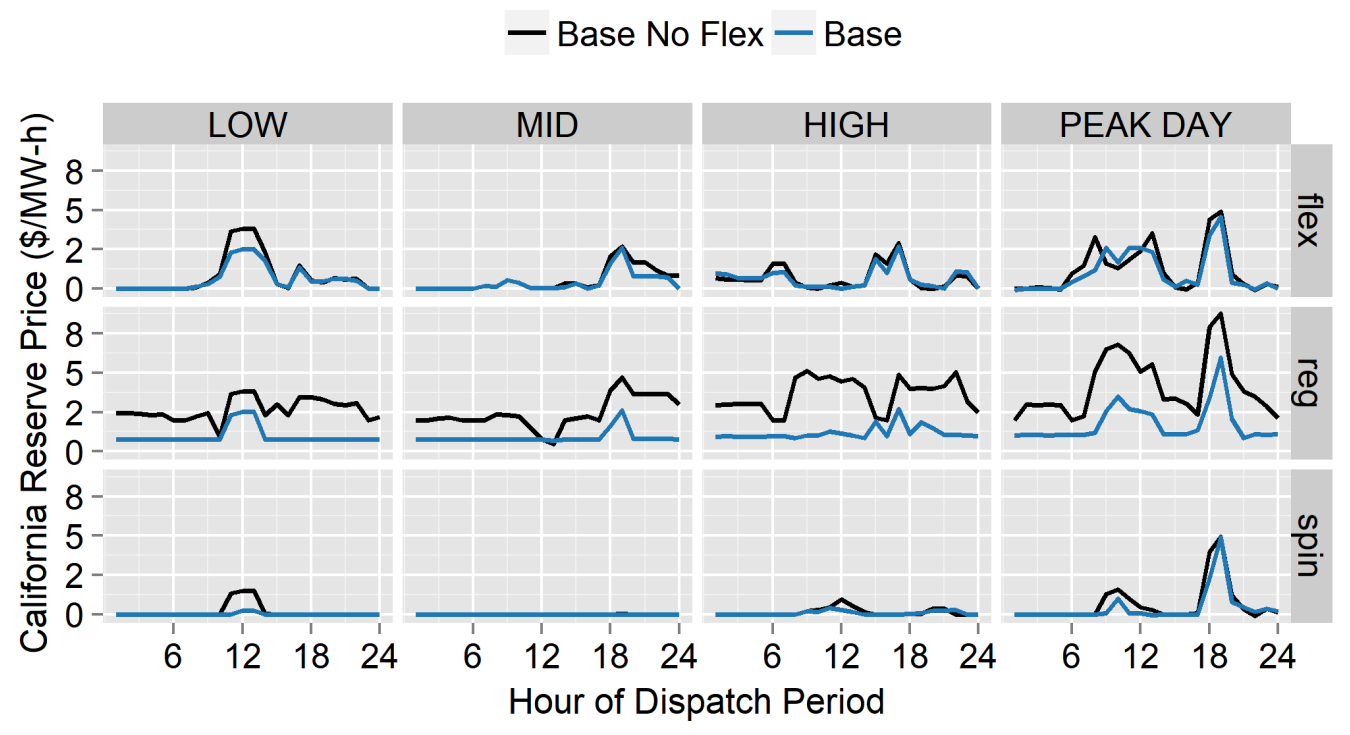

Figure 11. Base scenario reserve prices for California in 2030

This report is available at no cost from the National Renewable Energy Laboratory at www.nrel.gov/publications. 


\section{Conclusions}

RPM's approach to modeling flexible technologies is distinctive as compared to other capacity expansion models. RPM enables modeling short- and long-duration storage within the same framework by strictly modeling storage dispatch within a given representative day and enforcing energy capacity limits over multiple timescales. Accumulation of stored energy is scaled by dispatch period, and the accumulations are linked using a temporal transition matrix formulation (Tejada-Arango et al. 2018) that balances over the year. Grid-charged (BES) and renewable energy charged (CSP with TES) flexible technologies are both handled endogenously. Capacity credit and curtailment impacts for variable generators and flexible technologies are treated comprehensively, using time-synchronous 8760 data for wind generation, solar generation, and load; heuristic dispatch algorithms for BES and CSP with TES; and regression models of expected curtailment built from production cost model runs. The 8760 methods for estimating capacity credits and curtailment impacts most straightforwardly apply to pre-identified discrete system configurations and not for endogenous configuration determination. RPM therefore also includes post-processing pricetaker analyses that identify the most valuable BES and CSP with TES configurations for the specific system and conditions being studied. While this work was done with a prior version of RPM from 2018, the methods remain valid and useful for understanding flexible technologies in CEMs.

Pulling all of these model elements together for a focus region in the U.S. desert southwest directly impacted by California's energy storage mandate shows that capturing storage technologies with a robust representation of the electricity service values they provide can impact capacity decisions and dispatch expectations within a ten-year planning horizon. There are also plausible economic conditions under which such representations of BES and CSP with TES within planning models could have even large effects on the resulting technology mix. 


\section{References}

ABB. 2017. Velocity Suite - Market Intelligence Services (Energy Portfolio Management) | ABB. Visited on 10/11/2017. http://new.abb.com/enterprise-software/energy-portfolio-management/market-intelligence-services/velocity-suite.

Bistline, J., et al. 2020. "Energy storage in long-term system models: a review of considerations, best practices, and research needs". Progress in Energy 2 (3): 032001. doi:10.1088/2516-1083/ab9894.

Black, M., and G. Strbac. 2006. "Value of storage in providing balancing services for electricity generation systems with high wind penetration". Journal of Power Sources 162 (2): 949-953. Visited on 11/20/2015. doi:10.1016/j. jpowsour.2005.07.020.

Bloom, A., et al. 2016. Eastern Renewable Generation Integration Study. Technical Report. National Renewable Energy Laboratory. https://www.nrel.gov/docs/fy16osti/64472.pdf.

Breiman, L. 2001. "Random forests". Machine learning 45 (1): 5-32. doi:10.1023/A:1010933404324.

- . 2002. Manual On Setting Up, Using, And Understanding Random Forests V3.1. https://www.stat.berkeley.edu/ $\sim$ breiman/Using_random_forests_V3.1.pdf.

Brinkman, G., J. Jorgenson, J. Caldwell, and A. Ehlen. 2015. Low Carbon Grid Study: Analysis of a 50\% Emission Reduction in California. Technical Report NREL/TP-6A20-64884. National Renewable Energy Laboratory. https: //www.nrel.gov/docs/fy16osti/64884.pdf.

Cole, W. J., C. Marcy, V. K. Krishnan, and R. Margolis. 2016. "Utility-scale lithium-ion storage cost projections for use in capacity expansion models". In North American Power Symposium (NAPS), 2016, 1-6. IEEE. doi:10.1109/ NAPS.2016.7747866.

Denholm, P., J. Jorgenson, M. Hummon, T. Jenkin, D. Palchak, B. Kirby, O. Ma, and M. O’Malley. 2013. Value of Energy Storage for Grid Applications. Technical Report NREL/TP-6A20-58465. National Renewable Energy Laboratory. http://www.nrel.gov/docs/fy13osti/58465.pdf.

Denholm, P., J. Novacheck, J. Jorgenson, and M. O'Connell. 2016. Impact of Flexibility Options on Grid Economic Carrying Capacity of Solar and Wind: Three Case Studies. Technical Report NREL/TP-6A20-66854. National Renewable Energy Laboratory. http://www.nrel.gov/docs/fy17osti/66854.pdf.

E3. 2014. Investigating a Higher Renewables Portfolio Standard in California. Technical Report. Energy and Environmental Economics, Inc. (E3).

EIA. 2017. Annual Energy Outlook 2017 with projections to 2050. Tech. rep. U.S. Energy Information Association (EIA). Visited on 10/17/2017.

EnerNex Corporation. 2011. Eastern Wind Integration and Transmission Study (EWITS) (Revised). Subcontract Report NREL/SR-5500-47078. National Renewable Energy Laboratory. http://www.nrel.gov/docs/fy11osti/47078. pdf.

EPRI. 2014. Program on Technology Innovation: US-REGEN Model Documentation 2014. Technical Results 3002004693. Electric Power Research Institute (EPRI). http://www.epri.com/abstracts/Pages/ProductAbstract.aspx ?ProductId= 000000003002004693.

Fawagreh, K., M. M. Gaber, and E. Elyan. 2014. "Random forests: from early developments to recent advancements". Publisher: Taylor \& Francis, Systems Science \& Control Engineering: An Open Access Journal 2 (1): 602-609. doi:10.1080/21642583.2014.956265.

Frew, B. A., W. J. Cole, Y. Sun, T. T. Mai, and J. Richards. 2017. 8760-Based Method for Representing Variable Generation Capacity Value in Capacity Expansion Models: Preprint. Tech. rep. NREL/CP-6A20-68869. https: //www.osti.gov/scitech/biblio/1375305-based-method-representing-variable-generation-capacity-value-capacityexpansion-models-preprint.

GE Energy. 2010. Western Wind and Solar Integration Study. Subcontract Report NREL/SR-550-47434. National Renewable Energy Laboratory. http://www.nrel.gov/docs/fy10osti/47434.pdf.

Graves, F., T. Jenkin, and D. Murphy. 1999. "Opportunities for electricity storage in deregulating markets". The Electricity Journal 12 (8): 46-56. Visited on 11/20/2015. doi:10.1016/S1040-6190(99)00071-8.

Haas, J., F. Cebulla, K. Cao, W. Nowak, R. Palma-Behnke, C. Rahmann, and P. Mancarella. 2017. "Challenges and trends of energy storage expansion planning for flexibility provision in low-carbon power systems - a review". Renewable and Sustainable Energy Reviews 80:603-619. doi:10.1016/j.rser.2017.05.201. 
Hale, E, B. Stoll, and T. Mai. 2016. Capturing the Impact of Storage and Other Flexible Technologies on Electric System Planning. Technical Report NREL/TP-6A20-65726. NREL. http:/www.nrel.gov/docs/fy16osti/65726.pdf.

Hargreaves, J., E. Hart, R. Jones, and A. Olson. 2015. "REFLEX: An Adapted Production Simulation Methodology for Flexible Capacity Planning”. IEEE Transactions on Power Systems 30 (3): 1306-1315. doi:10.1109/TPWRS. 2014.2351235.

Ibanez, E., and M. Milligan. 2012. "Impact of transmission on resource adequacy in systems with wind and solar power”. In 2012 IEEE Power and Energy Society General Meeting. San Diego, California. https://www.nrel.gov/ docs/fy12osti/53482.pdf.

IEA. 2015. World Energy Model Documentation. Tech. rep. Paris, France: Organisation for Economic Co-operation and Development (OECD), International Energy Agency (IEA). https ://www . iea . org/reports / world - energy model/documentation.

Johnston, J., A. Mileva, J. H. Nelson, and D. M. Kammen. 2013. SWITCH-WECC Data, Assumptions, and Model Formulation. Tech. rep. University of California, Berkeley. http://rael.berkeley.edu/old_drupal/sites/default/files/ SWITCH-WECC_Documentation_October_2013.pdf.

Jorgenson, J., P. Denholm, M. Mehos, and C. Turchi. 2013. Estimating the Performance and Economic Value of Multiple Concentrating Solar Power Technologies in a Production Cost Model. Technical Report NREL/TP-6A2058645. National Renewable Energy Laboratory. http://www.nrel.gov/docs/fy14osti/58645.pdf.

Lew, D., et al. 2013. Western Wind and Solar Integration Study Phase 2. Technical Report NREL/TP-5500-55588. National Renewable Energy Laboratory. https:/www.nrel.gov/docs/fy13osti/55588.pdf.

Ma, J., V. Silva, R. Belhomme, D. Kirschen, and L. Ochoa. 2013. "Evaluating and planning flexibility in sustainable power systems". In 2013 IEEE Power and Energy Society General Meeting (PES), 1-11. doi:10.1109/PESMG. 2013.6672221.

Madaeni, S. H., P. Denholm, and R. Sioshansi. 2012. Comparison of Capacity Value Methods for Photovoltaics in the Western United States. Technical Report NREL/TP-6A20-54704. National Renewable Energy Laboratory. http: //www.nrel.gov/docs/fy12osti/54704.pdf.

Madaeni, S. H., R. Sioshansi, and P. Denholm. 2013. "Estimating the capacity value of concentrating solar power plants with thermal energy storage: A case study of the southwestern united states". IEEE Transactions on Power Systems 28 (2): 1205-1215. doi:10.1109/TPWRS.2012.2207410.

Mai, T., C. Barrows, A. Lopez, E. Hale, M. Dyson, and K. Eurek. 2015. Implications of Model Structure and Detail for Utility Planning: Scenario Case Studies using the Resource Planning Model. Technical Report NREL/TP-6A2063972. National Renewable Energy Laboratory. http://www.nrel.gov/docs/fy15osti/63972.pdf.

Mai, T., E. Drury, K. Eurek, N. Bodington, A. Lopez, and A. Perry. 2013. Resource Planning Model: An Integrated Resource Planning and Dispatch Tool for Regional Electric Systems. Technical Report NREL/TP-6A20-56723. National Renewable Energy Laboratory.

Murphy, C. A., Y. Sun, W. Cole, G. Maclaurin, C. Turchi, and M. Mehos. 2019. The Potential Role of Concentrating Solar Power within the Context of DOE's 2030 Solar Cost Targets. Technical Report NREL/TP-6A20-71912. National Renewable Energy Laboratory (NREL). https://www.nrel.gov/docs/fy19osti/71912.pdf.

NREL. 2017. 2017 Annual Technology Baseline. Data Set. National Renewable Energy Laboratory. Visited on 10/17/2017. https://atb.nrel.gov/electricity/2017/index.html.

- . 2018. 2018 Annual Technology Baseline. Data Set. National Renewable Energy Laboratory. https://atb.nrel.gov/ electricity/2018/index.html.

Pacheco, J. E., R. W. Bradshaw, D. B. Dawson, W. De la Rosa, R. Gilbert, S. H. Goods, M. J. Hale, P. Jacobs, S. A. Jones, and G. J. Kolb. 2002. Final test and evaluation results from the solar two project. Technical Report SAND2002-0120. Sandia National Laboratories. doi:10.2172/793226.

Palchak, D., and P. Denholm. 2014. Impact of Generator Flexibility on Electric System Costs and Integration of Renewable Energy. NREL Technical Report NREL/TP-6A20-62275. National Renewable Energy Laboratory. http: //www.nrel.gov/docs/fy14osti/62275.pdf.

Short, W., P. Sullivan, T. Mai, M. Mowers, C. Uriarte, N. Blair, D. Heimiller, and A. Martinez. 2011. Regional Energy Deployment System (ReEDS). Technical Report NREL/TP-6A20-46534. National Renewable Energy Laboratory. http://www.nrel.gov/docs/fy12osti/46534.pdf. 
Sigrin, B., M. Gleason, R. Preus, I. Baring-Gould, and R. Margolis. 2016. The Distributed Generation Market Demand Model (dGen): Documentation. Technical Report NREL/TP-6A20-65231. National Renewable Energy Laboratory (NREL). http://www.nrel.gov/docs/fy16osti/65231.pdf.

Sioshansi, R., S. H. Madaeni, and P. Denholm. 2014. "A Dynamic Programming Approach to Estimate the Capacity Value of Energy Storage". IEEE Transactions on Power Systems 29 (1): 395-403. doi:10.1109/TPWRS.2013. 2279839.

Sioshansi, R., P. Denholm, T. Jenkin, and J. Weiss. 2009. "Estimating the value of electricity storage in PJM: Arbitrage and some welfare effects". Energy economics 31 (2): 269-277. doi:10.1016/j.eneco.2008.10.005.

Stoll, B., E. Buechler, and E. Hale. 2017. "The value of demand response in Florida". The Electricity Journal, Energy Policy Institute's Seventh Annual Energy Policy Research Conference, 30 (9): 57-64. doi:10.1016/j.tej.2017.10.004.

Tejada-Arango, D. A., M. Domeshek, S. Wogrin, and E. Centeno. 2018. "Enhanced Representative Days and System States Modeling for Energy Storage Investment Analysis". Conference Name: IEEE Transactions on Power Systems, IEEE Transactions on Power Systems 33, no. 6 (): 6534-6544. doi:10.1109/TPWRS.2018.2819578.

Xu, B., J. Zhao, T. Zheng, E. Litvinov, and D. S. Kirschen. 2018. "Factoring the Cycle Aging Cost of Batteries Participating in Electricity Markets". Conference Name: IEEE Transactions on Power Systems, IEEE Transactions on Power Systems 33, no. 2 (): 2248-2259. doi:10.1109/TPWRS.2017.27333339. 


\section{A Regional Model}

RPM models a single interconnection; this study focuses on the Western Interconnection, which includes all or parts of 13 states in the western United States, two western provinces in Canada, and a small region of northern Mexico. This geographic boundary comprises 36 model BAs, which are the primary regional units in RPM. Embedded within this zonal structure, the model has a "focus region," within which generation units, transmission lines, and loads are represented with a high level of detail. Within this region, the optimization is carried out nodally, while the remaining regions are treated zonally to capture power transfers into and out of the focus region and between connected BAs. For this analysis, the focus region comprises three BAs that cover some of the highest-quality U.S. CSP resources: NEVP, SCE, and WALC (Figure A.1).

RPM also includes additional spatial layers to represent renewable resources. The model used here includes 67 solar, $52 \mathrm{CSP}$, and 36 wind resource areas in the Western Interconnection to describe the location-specific resource potential (developable area after accounting for various land use exclusions), performance (annual and hourly capacity factors), and grid interconnection distances. Additionally, distributed PV is added exogenously based on dGen projections (Sigrin et al. 2016). Resource regions are defined for each RPM model, that is, for each choice of focus region, with a greater density of resource regions placed within the focus region as compared to the remainder of the interconnect. This ensures that the region of interest is represented with high spatial resolution.

Underlying data for the start-year (2010) power system infrastructure are from the Western Wind and Solar Integration Study (WWSIS) Phase 2 (Lew et al. 2013). The table included in Figure A.1 presents the start-year capacities for the technologies modeled in RPM, as well as the amount of capacity added or under construction since 2010, and retirements prescribed exogenously to the model (Hale, Stoll, and Mai 2016).* Beyond prescribed new capacity, endogenous investment decisions for the type, amount, and location of new capacity are based on the needs of the system, policies, and economic factors.

* Since Hale, Stoll, and Mai (2016), Diablo Canyon Power Plant (2.2 GW), 0.8 GW of NG-CC, and a combined 1 GW of NG-CT were included in prescribed retirements (ABB 2017). 


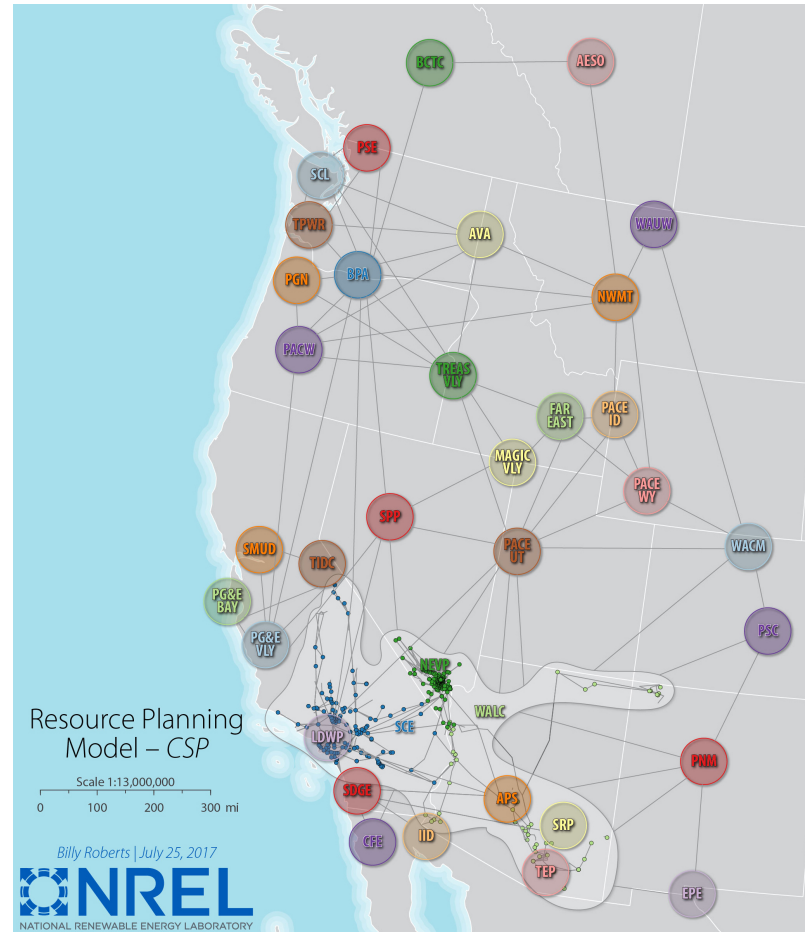

\begin{tabular}{lrrr|rrr|rrr}
\hline & \multicolumn{6}{c}{ WECC / Focus Capacity (GW) } \\
& \multicolumn{2}{c}{2010} & \multicolumn{3}{c}{ Planned } & \multicolumn{3}{c}{ Retiring } \\
\hline NG-CT & 39.7 & $/$ & 10.7 & 3.7 & $/$ & 1.7 & 16.7 & $/$ & 7.2 \\
Storage & 3.8 & $/$ & 0.2 & 0.0 & $/$ & - & - & $/$ & - \\
CSP & 0.4 & $/$ & 0.4 & 1.2 & $/$ & 0.9 & - & $/$ & - \\
PV & 1.2 & $/$ & 0.4 & 27.9 & $/$ & 9.9 & - & $/$ & - \\
Wind & 10.2 & $/$ & 0.3 & 6.6 & $/$ & 1.3 & - & $/$ & - \\
Oil & - & $/$ & - & 0.0 & $/$ & - & - & $/$ & - \\
Other RE & 4.6 & $/$ & 0.6 & 0.1 & $/$ & 0.0 & 0.0 & $/$ & - \\
NG-CC & 64.4 & $/$ & 12.2 & 1.9 & $/$ & 0.4 & 0.3 & $/$ & - \\
Hydro & 70.2 & $/$ & 5.2 & 0.1 & $/$ & - & 0.0 & $/$ & - \\
Coal & 38.8 & $/$ & 1.2 & 0.4 & $/$ & - & 9.8 & $/$ & 0.6 \\
Nuclear & 9.7 & $/$ & 2.2 & - & $/$ & - & 4.5 & $/$ & 2.2 \\
\hline Total & 243.0 & $/$ & 33.5 & 42.1 & $/$ & 14.2 & 31.4 & $/$ & 10.1 \\
\hline
\end{tabular}

Figure A.1. RPM is a combined nodal-zonal model for examining regional planning decisions.

The focus region for this paper is centered on the United States' highest quality CSP resource.

This report is available at no cost from the National Renewable Energy Laboratory at www.nrel.gov/publications. 


\section{B Technology Cost Assumptions}

RPM makes investment decisions based on a number of assumptions. We include the federal renewable energy tax credits, state renewable portfolio standards, and California's storage mandate, but not California's carbon cap and trade program, existing demand response programs, or local incentives. Cost data for new natural gas-fired and wind capacity are consistent with those found in NREL's 2017 Annual Technology Baseline (ATB) mid case, Table B.1 (NREL 2017). ${ }^{\dagger}$ The ATB mid and low price trajectories are use for solar technologies, particularly utility-scale PV and CSP with TES. Battery price trajectories are taken from Cole et al. (2016). Fuel prices are from the Energy Information Administration's Annual Energy Outlook 2017 reference case (EIA 2017).

Table B.1. Technology capital cost assumptions for new generation capacity

\begin{tabular}{lrrrrr}
\hline Overnight Capital Costs $(2010 \$ / \mathrm{kW})$ & 2015 & 2020 & 2025 & 2030 & 2035 \\
\hline Natural Gas-Combined Cycle & 941 & 918 & 904 & 876 & 860 \\
Natural Gas-Combustion Turbine & 804 & 784 & 772 & 744 & 730 \\
Wind (Best Resource Class) & 1531 & 1477 & 1441 & 1427 & 1421 \\
Wind (Worst Resource Class) & 1649 & 1634 & 1624 & 1620 & 1619 \\
PV Fixed-Tilt & 1653 & 1211 & 900 & 843 & 797 \\
PV Single-Axis Tracking & 1746 & 1302 & 992 & 935 & 889 \\
\hline
\end{tabular}

Battery storage configurations were chosen to allow for a variety of grid service needs to be met through battery configurations. Very short duration storage is valuable for providing reserves, whereas longer duration storage is more valuable for energy shifting and curtailment reduction. We selected several configurations, with energy storage capacities ranging from 0.25 hours to 8 hours to allow the model a variety of options to meet the particular needs of each region and scenario. Table B.2 lists the storage configurations and their costs in the mid-range case.

Provision of several grid services is restricted based on the amount of storage a battery has. All batteries are allowed to charge and discharge, so can provide energy up to the amount of energy in storage at each time. Regulation reserves provision is also allowed for all storage types. Spinning reserves are, however, limited to only those configurations with at least $20 \mathrm{~min}$ of storage, and flexibility reserves are only allowed for configurations with at least $1 \mathrm{~h}$ of storage. This is to ensure these resources could meet all regulations for providing these types of reserves. Additionally, firm capacity credit is determined by the capacity value calculation described above, which is dependent on the number of hours of storage. In general, longer duration storage has a higher capacity value. Curtailment reduction potential is also determined by the number of hours of storage, with longer duration storages more able to reduce curtailment.

The carbon prices used for the HCF\&CSP scenario were compiled by using the 75th percentile of the non-zero carbon price trajectories in https://resourceplanning.lbl.gov in 2017. This led to the carbon price trajectory shown in Figure B.1.

${ }^{\dagger}$ Real 2010 dollars are used throughout this report unless otherwise noted. 
Table B.2. Battery storage configurations and costs

\begin{tabular}{|c|c|c|c|c|c|c|c|}
\hline \multirow[b]{2}{*}{$\begin{array}{l}\text { Duration } \\
\text { (h) }\end{array}$} & \multirow[b]{2}{*}{ Description } & \multicolumn{6}{|c|}{ Capital Costs $(\$ / k W h)$} \\
\hline & & 2010 & 2015 & 2020 & 2025 & 2030 & 2035 \\
\hline 0.25 & $\begin{array}{l}\text { Very short duration, reg. } \\
\text { reserves }\end{array}$ & 3290 & 2857 & 2529 & 2268 & 2048 & 1838 \\
\hline 0.5 & $\begin{array}{l}\text { Short duration, reg. } \\
\text { reserves }\end{array}$ & 1972 & 1624 & 1391 & 1236 & 1116 & 1006 \\
\hline 1 & Mostly reserves provision & 1323 & 1007 & 825 & 720 & 650 & 591 \\
\hline 2 & $\begin{array}{l}\text { Reserves and peak energy } \\
\text { capacity }\end{array}$ & 1008 & 699 & 541 & 462 & 417 & 383 \\
\hline 4 & $\begin{array}{l}\text { Energy arbitrage, flex } \\
\text { reserves }\end{array}$ & 855 & 545 & 400 & 333 & 301 & 279 \\
\hline 8 & $\begin{array}{l}\text { Longer duration energy } \\
\text { arbitrage }\end{array}$ & 780 & 468 & 330 & 268 & 243 & 227 \\
\hline
\end{tabular}

Table B.3. Modeled CSP with TES configurations and costs

\begin{tabular}{cccccc}
\hline SM & \multirow{2}{*}{$\begin{array}{c}\text { Storage } \\
\text { (h) }\end{array}$} & \multicolumn{4}{c}{ Overnight Capital Costs (2010\$/kW) } \\
& 2020 & 2025 & 2030 & 2035 \\
\hline 1.8 & 8 & $4488 / 4488$ & $3230 / 2916$ & $2916 / 2688$ & $2916 / 2524$ \\
2.5 & 7 & $5059 / 5059$ & $3671 / 3324$ & $3324 / 3065$ & $3324 / 2879$ \\
2.7 & 9 & $5515 / 5515$ & $3927 / 3530$ & $3530 / 3262$ & $3530 / 3069$ \\
3.3 & 14 & $6754 / 6754$ & $4638 / 4110$ & $4110 / 3815$ & $4110 / 3603$ \\
\hline
\end{tabular}

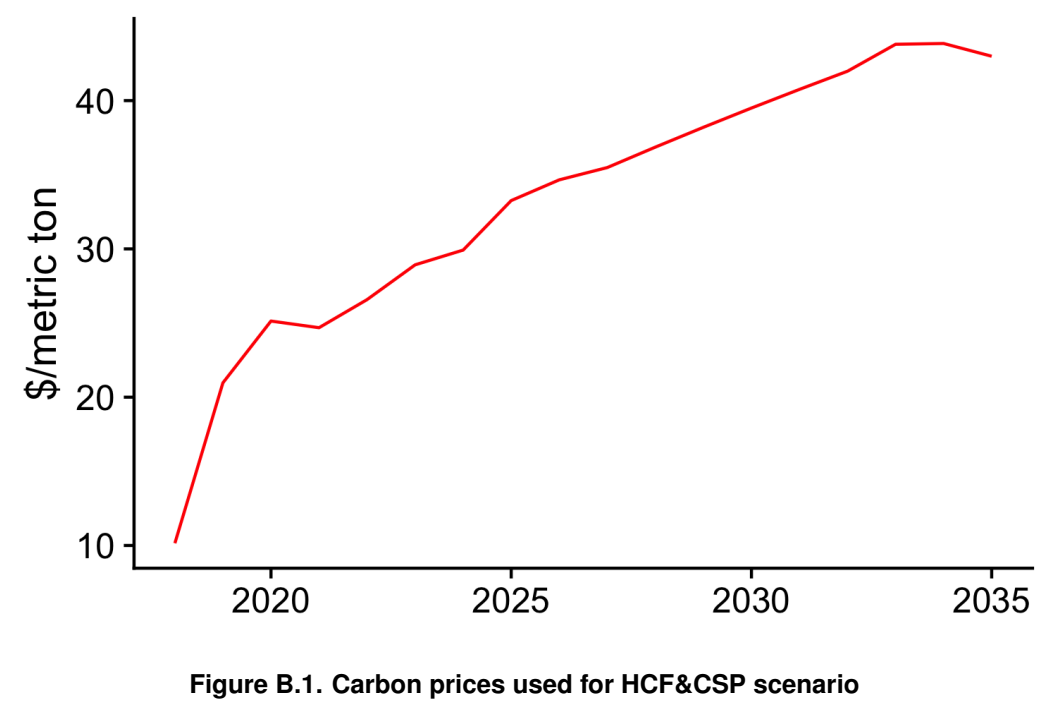

This report is available at no cost from the National Renewable Energy Laboratory at www.nrel.gov/publications. 


\section{Pricetaker Analyses to Determine Optimal Configurations}

The BES and CSP with TES configuration options offered to RPM are chosen by running pricetaker analyses using the marginal costs output by RPM scenarios. Those analyses choose the configurations in terms of energy capacity $e$ and solar multiple SM (CSP only) that maximize net revenue defined by

$$
\begin{aligned}
p_{\text {capacity }} \cdot \text { CapacityCredit } & +\sum_{t} p_{\text {energy }}(t) \cdot(\operatorname{Generation}(t)-\operatorname{NetUnderage}(t))+\sum_{t, \text { reserve }} p_{\text {reserve }}(t) \cdot \operatorname{Reserve}(t) \\
& - \text { CapitalCost }- \text { FixedO\&M }- \text { VariableO\&M } \cdot \sum_{t} \operatorname{Generation}(t)
\end{aligned}
$$

This is done for an incremental resource of an assumed size, $100 \mathrm{MW}$ by default. The dispatch models for BES and CSP with TES mirror the models used in RPM; however, capacity credit and curtailment impacts are captured differently.

To determine capacity credit, the top-hours method described in the main body of the paper is embedded directly in the pricetaking optimization formulation by calculating the "overage" and the "net overage" as:

$$
\begin{aligned}
\text { Overage }(t) & \geq \operatorname{NetLoad}(t)-\tau \\
\operatorname{NetOverage}(t) & =\text { Overage }(t)-\max (\operatorname{load}(t)-\tau, 0)
\end{aligned}
$$

where overage is also required to be non-negative, and the threshold $\tau$ is equal to the load in the last top hour (the 100th hour by default) minus the resource power capacity $C$. Any net load over this threshold has a chance at contributing to the top hours after the new resource is dispatched. The capacity credit is then equal to:

$$
\text { CapacityCredit }=\frac{\sum_{t}-\operatorname{NetOverage}(t)}{\sum_{t} \min (C, \max (\operatorname{load}(t)-\tau, 0))} ;
$$

where the denominator on the right-hand side is the expected net overage, that is, the maximum possible contribution the new resource can make to reducing load in the top hours as defined by the threshold $\tau$.

Curtailment is accounted for with a similar construct we refer to as "underage." In this case, RPM reports a regional system minimum generation point, and we interpret any net load that falls below this level as curtailment of renewable generation. The original load may imply an initial level of curtailment. The dispatch of the incremental BES or CSP with TES resource then has the opportunity to either reduce that curtailment or contribute additional curtailment. These concepts become

$$
\begin{aligned}
\text { Underage }(t) & \geq \operatorname{mingen}-\operatorname{NetLoad}(t) \\
\operatorname{NetUnderage}(t) & =\operatorname{Underage}(t)-\max (\operatorname{mingen}-\operatorname{load}(t), 0)
\end{aligned}
$$

where, like overage, underage is also a non-negative quantity. The net underage is then used in the objective function to make sure that the resource is not paid for generation during times of curtailment, and also does not have to pay (in the case of BES) to charge from the grid during times of curtailment. 